\title{
PSYCHOLOGICAL ANTECEDENTS OF RISK-TAKING BEHAVIOR IN CONSTRUCTION
}

\author{
by \\ Antoine Jean-Pierre Tixier \\ University of Colorado, 2013
}

\begin{abstract}
A thesis submitted to the
Faculty of the Graduate School of the

University of Colorado in partial fulfillment

of the requirements for the degree of

Master of Science in Civil Engineering

Department of Civil, Environmental, and Architectural Engineering
\end{abstract}

2013 
This thesis entitled:

Psychological Antecedents of Risk-Taking Behavior in Construction written by Antoine Jean-Pierre Tixier

has been approved by the Department of Civil, Environmental and Architectural Engineering

Dr. Matthew Hallowell (Chair)

Dr. Amy Javernick-Will

\section{Dr. Paul Goodrum}

July, 04, 2013

The final copy of this thesis has been examined by the signatories, and we find that both the content and the form meet acceptable presentation standards of scholarly work in the above mentioned discipline.

IRB protocol \# 12-0640 


\begin{abstract}
Tixier, Antoine Jean-Pierre (M.S. Civil Engineering)

Psychological Antecedents of Risk-Taking Behavior in Construction

Thesis directed by Professor Matthew R. Hallowell.
\end{abstract}

Our study aimed at testing the impact of emotions on construction risk perception in an occupational-like context. To achieve this objective, we induced different positive and negative emotions in 68 Civil, Environmental and Architectural Engineering students at the University of Colorado at Boulder, using validated movie excerpts. Then, subjects' emotional states were measured using a validated questionnaire. Following the emotional state measurement, participants' risk perceptions were objectively quantified using a standardized survey embedded within a highly realistic three dimensional virtual environment. This environment, known as SAVES, was created from the building information model of a process plant and over 200 photographs of actual industrial construction projects to ensure a high level of immersion. The measures of emotions served as the independent predictor variables and the risk perception measures served as the dependent variable. Once these data were collected, Principal Component Analysis was used to reduce the dimensions of the predictor variables and differences in risk perception between principal components were tested using the Mann-Whitney U test. The results of these analyses indicated that risk perception differed statistically significantly $(p=.009$ and $p=.003$, respectively) between the positive group (happy, amused, joyful, and interested subjects) and the negative group (sad and unhappy subjects), and between the positive group and the self-protective group (fearful, anxious and disgusted subjects). Risk perception differed also greatly between the neutral group and the negative and self-protective groups $(\mathrm{p}<0.003)$. No statistical differences in risk perception were found between the neutral group and the positive group or between the negative and the self-protective groups. 
Interestingly, the negative and the self-protective groups perceived on average almost three times more risk than the neutral and positive groups.

\section{ACKNOWLEDGEMENTS}

I would like to thank Professor Matthew R. Hallowell, for his extensive guidance and support as my advisor, and for providing me with a Research Assistant position which was immensely appreciated. As a civil engineering student, I really enjoyed conducting a totally exploratory, interdisciplinary study involving psychology and construction, and I would like to thank Dr. Hallowell for providing me with this very interesting research opportunity. I did learn a lot. I would also like to extend my gratitude to Professor Leaf Van Boven from the department of Psychology for all his time, help and advice, and to my other committee members, Professor Amy Javernick-Will and Professor Paul Goodrum, for their thoughtful insight and suggestions on my research.

I also thank all the Construction Safety Laboratory members, and especially Daniel Hansen and Alex Albert, whose help was much appreciated during the course of this project.

Last but not least, I can't be thankful enough to my grandmother Michele and my father Daniel for their unlimited support. 


\section{CONTENTS}

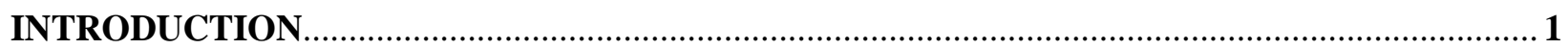

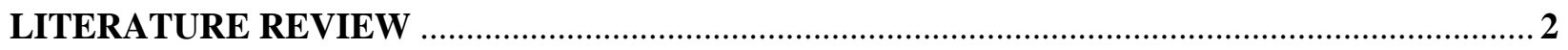

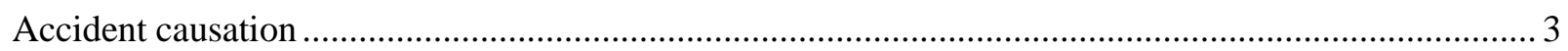

Limitations in the body of knowledge and point of departure ...................................................... 3

Situational awareness and the role of risk perception in decision-making under uncertainty .................. 4

Limitations in the body of knowledge and point of departure ......................................................... 4

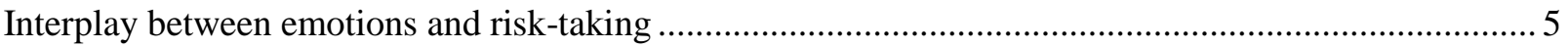

Limitations in the body of knowledge and point of departure ......................................................... 7

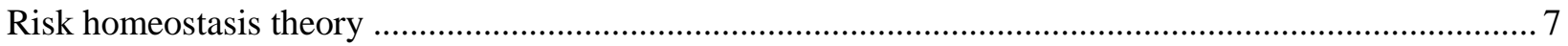

Risk-taking as a method to cope with undesirable emotions ............................................................... 8

Interaction between experience, risk perception, risk valuation, and risk-taking behavior ...................... 9

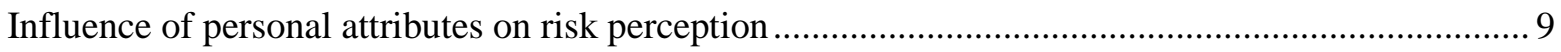

Influence of group culture on risk perception ............................................................................. 10

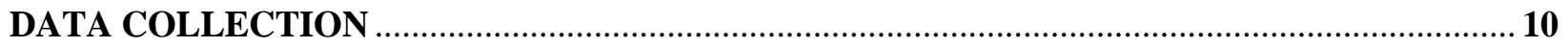

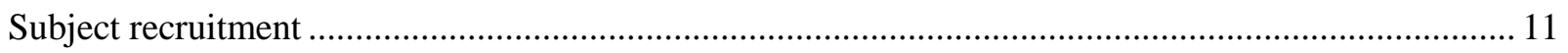

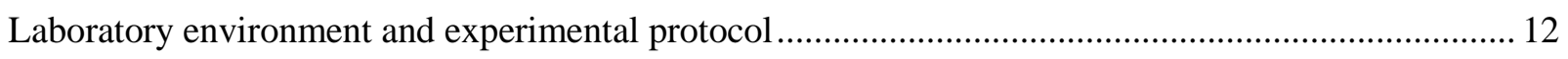

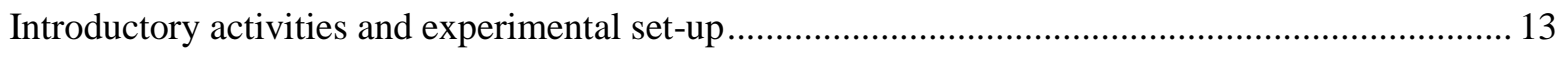

Inducing and measuring emotions (independent variables) ......................................................... 14

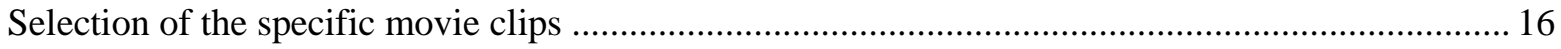

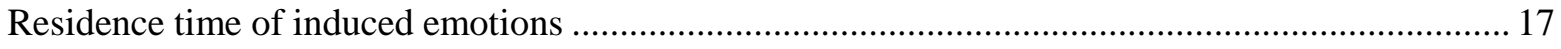

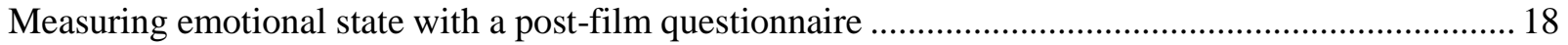

Measuring risk perception using a standardized data collection strategy embedded in a highly realistic

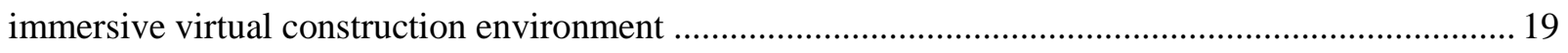

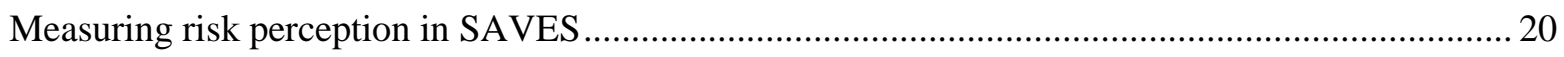

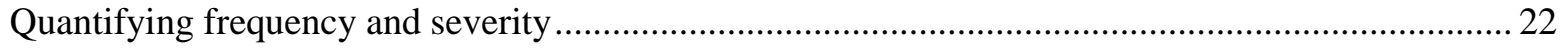

Obtaining a score using a risk perception table ............................................................................. 23

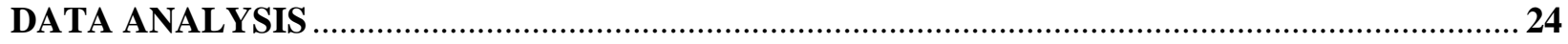

Clustering emotions using Principal Component Analysis ........................................................... 25

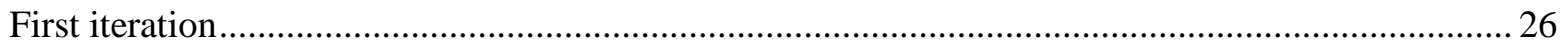

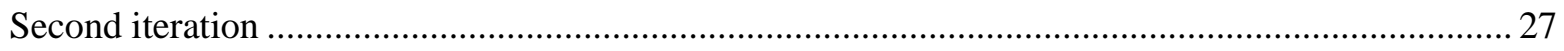

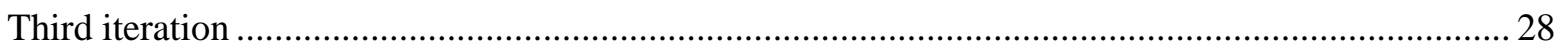


Accepting the three-factor model from the third iteration .......................................................... 29

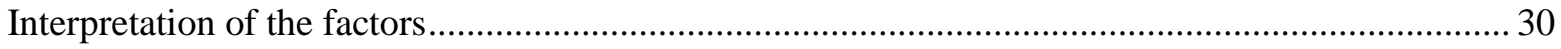

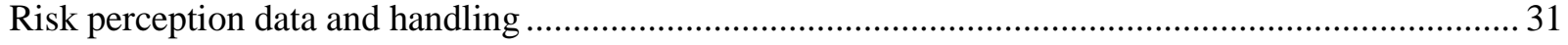

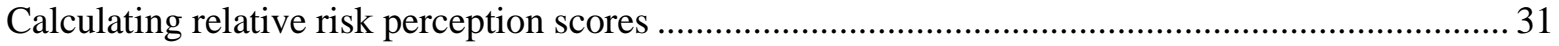

Testing for differences between group of emotions using multiple Mann-Whitney U tests.................. 32

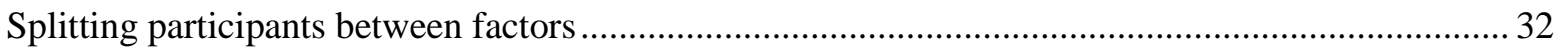

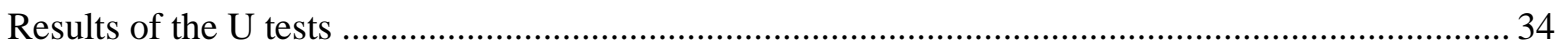

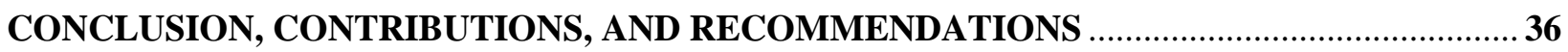

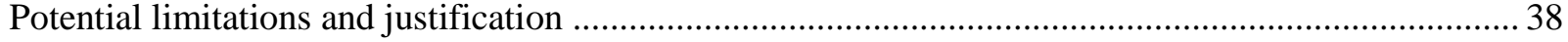

REFERENCES

APPENDIX 


\section{INTRODUCTION}

Despite the improvements that followed the inception of OSHA in 1970 and the diffusion of best practice, construction still remains one of the most dangerous industries in the U.S., employing $7 \%$ of the national workforce but accounting for $17 \%$ of all work-related deaths (Bureau of Labor Statistics 2011). It is estimated that there are over 1,000 fatalities and 230,000 injuries each year that result in over $\$ 15$ billion in direct costs (Bureau of Labor Statistics 2011), which equates to $15 \%$ of the costs for all commercial construction (Waehrer et al. 2007). Agarwal and Everett (1997) have estimated that worker compensation premiums account for $1.5 \%$ to $6.9 \%$ of total costs of new construction. In a more recent, compelling example of the economic impacts of injuries to construction organizations provided by the Center for Construction Research and Training (2002), a construction company operating at a $3 \%$ profit margin would have to increase sales by $\$ 333,000$ to pay for a $\$ 10,000$ injury. According to Howell et al. (2002), accidents will occur even when comprehensive safety programs are in place because workers voluntarily take risks. Hinze (2006) showed that over $75 \%$ of construction injuries were caused by unsafe worker actions. Carter and Smith (2006) claimed that risk-taking behavior is a symptom of workers' inability to adequately perceive and respond to risk. Thus, understanding the psychological factors influencing risk perception is important to long-term safety improvement. In the past, accident causation models have focused on studying unsafe conditions and unsafe human behaviors that contribute to injuries. However, behavioral models focused primarily on

human error (Reason 1990, Petersen 1982, Recht 1970, Swain et al. 1963) and personal traits that were thought to result in accident proneness (Klumb 1995, International Labor Organization 1983). 
However, none of these approaches considered emotional antecedents of hazardous behaviors, despite the fact that emotions have been shown to play an essential role in hazard recognition, risk perception, and risk-based decision-making. Building on construction safety, behavioral and cognitive psychology theories, we aim to address this knowledge gap by measuring the influence of positive and negative emotions on risk perception in a highly realistic, complex, and dynamic construction environment. Such new knowledge will contribute to a better understanding of the psychological aspects of human unsafe behavior, testing the translation of traditional psychological theories into an occupational context. In practice, enhanced knowledge of risk perception has the ability to improve nearly all injury prevention activities, ranging from job hazard analyses to prevention through design.

\section{LITERATURE REVIEW}

In order to understand how this study is built upon and departs from current knowledge, we have reviewed relevant literature in the areas of accident causation, situational awareness, and the interplay between emotions, risk perception and risk-taking. Accident causation models unequivocally include the decision-making process as a fundamental causal component. The act of detecting, comprehending, projecting and making decisions in a very complex and dynamic environment such as construction safety is known as situational awareness. An important component of situational awareness is a worker's ability to accurately perceive risks. Unfortunately, despite the fact that it is critical to understand why workers make specific decisions when faced with hazards, there is a dearth of knowledge of the psychological factors that affect risk perception in real-life contexts. In this study, we aim to address this knowledge gap by exploring the relationship between emotional states and relative levels of perceived risk. 
Because the construction domain is devoid of rigorous empirical investigations into the psychology of risk-taking behavior in general, this literature review includes findings from many industries and non-occupational contexts.

\section{Accident causation}

Traditional accident causation models include sequential models such as Heinrich's Domino theory (Heinrich et al. 1980), where an accident is held to be the result of a chain of events, a crucial link of this chain being unsafe worker behavior. Epidemiological accident causation models, such as Reason's (1990) Swiss cheese model, view accidents as provoked by a combination of immediate and latent factors, belonging to three general categories, namely errors in design, management, and worker action. Other theories, such as Hinze's (1997) mental distraction theory, focus on the individual to explain why accidents occur. According to accident proneness theories (e.g., Dahlback 1991), certain workers are more likely to be involved in accidents because of personal risk-taking traits. Finally, for system-based models, accidents can be explained by a network of technical, human, organizational and managerial components (Perrow 1984).

\section{Accident causation: Limitations in the body of knowledge and point of departure}

All the aforementioned theories claim that accidents originate from various environmental, technical, and human factors, the latter playing a central role. However, even though these models acknowledge the existence of external and internal pressures at the individual's level, such as management and personal issues, none try to explain the underlying mechanisms that lead workers to behave unsafely. 


\section{Situational awareness and the role of risk perception in decision-making under uncertainty}

In human factors engineering, situational awareness is defined as a motivated, active, and continuous extraction of information from an environment and the ability to use experience to anticipate consequences of an action and act effectively (Artman 2000). Situational awareness is a three-step process which includes detection of hazardous signals, perception and comprehension of the risks associated with the hazard, and projection of the consequences associated with the decision options (Endsley 1995, Smith and Hancock 1995, Sarter and Woods 1991). Risk perception (Level II) is fundamental (Zimolong 1985) because, even if hazards are identified (Level I), workers may involuntarily behave unsafely when they inaccurately perceive and value risk.

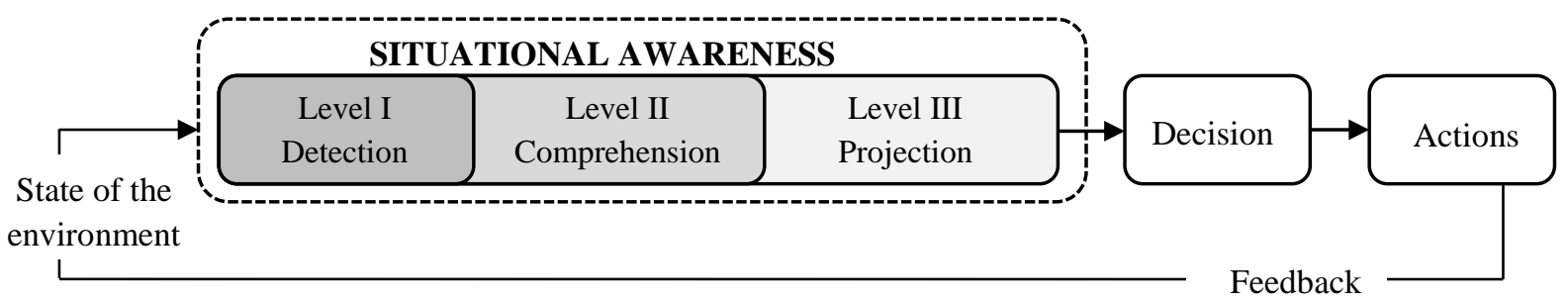

Figure 1 - Conceptual model of situational awareness

\section{Situational awareness: Limitations in the body of knowledge and point of departure}

Psychologists hypothesize that emotions greatly influence signal detection, risk perception, and the process of risk-based decision-making as a whole. Unfortunately, researchers have yet to reach consensus regarding the nature of these emotional interferences. Also, there is a dearth of studies that validate theory in real life contexts. This study contributes to the ongoing debate with an objective experiment that measured the relationship between emotion and risk perception within a virtual yet highly realistic occupational-like environment. 


\section{Interplay between emotions and risk-taking}

According to Clore et al. (1994) emotions are mental, internal affective states that refer to how a person feels and what the feeling is about. For Loewenstein and Lerner (2003), there are two types of immediate emotions: incidental emotions and integral emotions. Incidental emotions are unrelated to a specific choice that must be made but influence the choice (Pfister and Böhm 2008). For example, a worker who is very angry because he just got reprimanded by his supervisor for arriving to work late may take more safety risks if experiencing an emotion incidental to the reprimand. Alternatively, integral emotions are experienced when one considers the potential positive or negative outcomes of a decision (Schwarz and Clore 2007). For example, a worker may be fearful when not using a fall arrest system. Emotions have been shown to impact risk-based decision-making by directly acting on cognitive processes of decision-making and indirectly by influencing risk perception (Clore et al. 1994). The relationship between emotions and risk-taking is also bidirectional because engaging in risky activities gives birth to emotional experiences (Bonnet et al. 2008). Researchers have provided physiological evidence that emotions affect cognition and risk-taking decisions in some way. Using Positron Emission Tomography, Drevets and Raichle (1998) observed that brain blood fluxes decreased in the areas mainly dedicated to risk-based decision-making when intense emotional states were induced. Bechara et al. (1997) found corroborating evidence that individuals with brain damage in the prefrontal cortex, the area of the brain which controls decision-making, were unable to develop the necessary emotional anticipatory reactions that subconsciously guide risk-taking behavior. Interestingly, this assertion is also supported by Patrick (1994) who demonstrated that an explanation for psychopath engagement in abnormal 
risk-taking behaviors is their inability to fully experience anticipatory negative emotions such as fear and anxiety when contemplating the outcomes of risky choices.

Many theoreticians have made claims about the role of emotions in risk-perception and riskbased decision-making. For example, Finucane et al. (2000) proposed that an "affect heuristic" may influence general risk perception when a certain event (such as an earthquake) is described in terms of a tragic outcome. Keller et al. (2006) suggest that people use their emotions as a way to estimate the probability of occurrence of an adverse event, and that evoking a negative affect associated with the event may result in a greater perceived risk. Loewenstein et al.'s (2001) riskas-feelings hypothesis posits that specific emotions, such as worry, fear, dread, and anxiety, guide human responses to dangerous situations. For instance, fear was demonstrated to activate self-protective processes associated with risk aversion (Öhman and Mineka 2001). Likewise, Johnson and Tversky's (1983) affective generalization hypothesis, supported by DeSteno et al. (2000), and Schwarz and Clore (1983) suggests that emotions influence decision-making because they inform individuals about the current state of their environment. The subconscious impact of emotional messages on judgment is thought to be even more significant in situations where a risk-based decision must to be made under high pressure and time constraints (LeDoux 1996, Bargh 1984).

Even though theoreticians broadly agree that there is a strong relationship between emotions and risk-taking, studies have produced equivocal results regarding the nature of this relationship. Some of the salient findings from psychology literature are as follows:

- Participants with positive emotional states were more risk averse than neutral people when potential losses were large (Nygren et al. 1996), 
- Participants with positive emotional states were prone to take higher risks than neutral people when potential losses were low (Isen and Patrick 1983),

- Participants who were depressed were more risk averse that participants with neutral or positive emotional states (Yuen and Lee 2003),

- Participants who were anxious were more risk averse than their low-anxiety counterparts (Eisenberg et al. 1995).

\section{Interplay between emotions and risk perception: Limitations in the body of knowledge and}

\section{point of departure}

It is clear that emotions play a significant role in risk-based decision-making, especially with respect to risk perception. However, it is also clear that the relationship between emotions and risk-taking is not completely understood and that because most of the research stated above was conducted through artificial contexts such as gambling tasks or scenarios, there is a need for studies were consequences of actions are directly applicable to real-life.

\section{Risk homeostasis theory}

The risk homeostasis theory, also known as the risk compensation theory, was initially proposed by Wilde (1982). This cost-benefit model posits that people constantly adapt their behavior in order to be continuously subjected to the same level of perceived risk within their environment. For instance, Adams (1995) found that drivers who wear seatbelts are more likely to drive at a faster speed than when they do not wear a seatbelt. Similarly, Bianchi et al. (2010) found that helmet wearers take more risks on ski slopes than when they are bare-headed. Wilde (1998) provided additional support for his theory by longitudinally observing driver behavior and traffic 
accidents in Sweden following the change from left to right-hand driving. Immediately following the change, the fatality rate dropped dramatically; however, after only 18 months, it returned to its original level. This observation can be explained by the fact that initially, drivers perceived the risks associated with right-hand driving to be high, and compensated accordingly by driving prudently. However, after a while, they became accustomed to right-hand driving, felt safer, and then, took increasing risks until they returned to the same level of risk-taking as before. Validated the risk homeostasis theory in the construction industry, Aranda and Finch (2003) showed that construction workers became overconfident and took higher risks when safety measures such as training sessions, protective gear, or site devices were implemented, because they felt safer. This compensation phenomenon explains the difficulties that construction professionals may face when implementing safety systems or procedures that decrease workers' risk perception. More broadly, the construction industry has to understand why people behave unsafely to ensure the long-term success of safety interventions.

\section{Risk-taking as a method to cope with undesirable emotions}

Although emotions influence risk-taking, risk-taking can give birth in turn to emotional episodes. Some research suggests that consequently, the search for certain emotional states alone can be the reason that leads people to take risks. For example, risk-taking scuba divers reported experiencing more positive emotions (happiness) and less negative emotions (anger, discouragement, disgust) than their counterparts after a high risk dive, as shown in Bonnet et al. (2008). The implication is that engagement in hazardous behaviors may be a path for some risktakers to get rid of their unwanted emotions and to reach more desirable states. These results are consistent with prior findings that revealed that people take or avoid risks as a subconscious way 
to regulate their emotions (Cooper et al. 2003). Observed engagement in emotional regulating risk-taking behavior includes smoking (Frone and Windle 1997), aggressive driving (Styles et al. 2005), drinking (Fromme and Rivet, Westen 1994), and hazardous sexual behaviors (Semple et al. 2000, Folkman et al. 1992).

\section{Interaction between experience, risk perception, risk valuation, and risk-taking behavior}

When evaluating risks, people tend to be subjected to what Kahneman and Lovallo (1993) call the arrogance of optimism or the illusion of control. By the same token, Sjöberg (2000) propose that people are inherently and subconsciously optimistic about their environment and the expected outcomes of their own decisions. Interestingly, Slovic (1987) found that risks perceived to be voluntary, or to have clear benefits were generally preferred to risks that were perceived to be imposed, and to have very little or no benefit.

\section{Influence of personal attributes on risk perception}

Wildavsky and Dake (1990) reviewed the body of literature related to general risk perception and found that the influencing factors include, but are not limited to: individual characteristics, economics, culture, politics, and knowledge of the situation. Of the personal characteristics, experience, skills, and knowledge of the environment are the most impactful (Greene et al. 2000). For example, Christensen and Glad (1996) studied drivers of semi-trailer trucks in Norway who were required to take a mandatory course for winter driving and found that trained participants took higher risks because of their increased driving skills and experience. Similarly, Bianchi et al. (2010) and Ruedl et al. (2009) found that skilled skiers and snowboarders were inclined to take much higher risks than their less skilled counterparts and McCarthy and Talley 
(1999) observed that recreational sailors with 100 hours or more at the helm were more likely to behave unsafely at sea, such as drinking alcohol while sailing. Finally, Hunter (2002), in accordance with Williams (1999), found that both very experienced aircraft pilots and student pilots underestimate risks, respectively because of their overconfidence and insufficient knowledge. Consistent with these findings, Lester \& Bombaci (1984) found a belief of invincibility to be responsible for hazardous attitudes among pilots. In the context of construction, Zimolong (1985) found that experienced iron workers significantly underestimated the likelihood of being injured.

All the previous findings can be explained by the "zero risk theory" (Summala 1988, Naatanen and Summala 1974), which holds self-confidence to increase and risk perception to decrease (to the point of zero perceived risk) with experience. In other words, experienced drivers, skiers, airplane pilots, or iron workers, may feel there is no real risk at all. Likewise, Styles et al. (2005) and Fuller (1984) found that, over time, risky actions may be perceived to become less risky by people who have already taken such actions without suffering from any negative consequence. Kahneman and Lovallo (1993) claim that risk perception is much more accurate when the decision-maker can separate themselves from the environment and adopt an objective, comparative, and systematic viewpoint.

The implications of these past studies are that risk perception cannot be linked to one characteristic. Rather, risk perception must be considered in the context of an individual's overall profile with respect to a situation. Regardless of the precursors to risk perception, the comparative value of a risk that individuals perceive will impact their risk-taking behavior. 


\section{Influence of group culture on risk perception}

In addition to personal factors, risk perception is also influenced by social interaction and shared culture. As Adams (1995) said, "Risk is culturally constructed. Where scientific fact falls short of certainty, we are guided by assumption, inference, and belief'. According to Wahlberg and Sjöberg (2000), general risk perception, a dimension of culture, differs widely from personal risk perception, and is generally not accurate (Slovic et al. 2002). However, construction safety decisions are typically made by individuals or small ad hoc groups. Thus, the interplay among personal characteristics, social characteristics, and risk perception is very important.

\section{DATA COLLECTION}

In order to test the hypothesis that there is no relationship between emotional state and perceived risk, we designed and executed a controlled experiment in an augmented virtual environment. Our data collection goals were to: (1) induce specific emotional states using highly effective video clips, (2) objectively measure emotional states with a validated questionnaire, and (3) objectively measure risk perception using a validated scale and operational definitions of potential outcomes. Once these data were collected, we aimed to use multivariate statistics to reduce the dimensions of our dataset and measure relationships between emotional states and risk perceptions. Here we review the details of the data collection process, with particular emphasis on the subject recruitment, experimental design, and the valid and reliable measurement of the independent variables (emotions) and the dependent variable (risk perception). The overarching research approach is illustrated in Figure 2. 


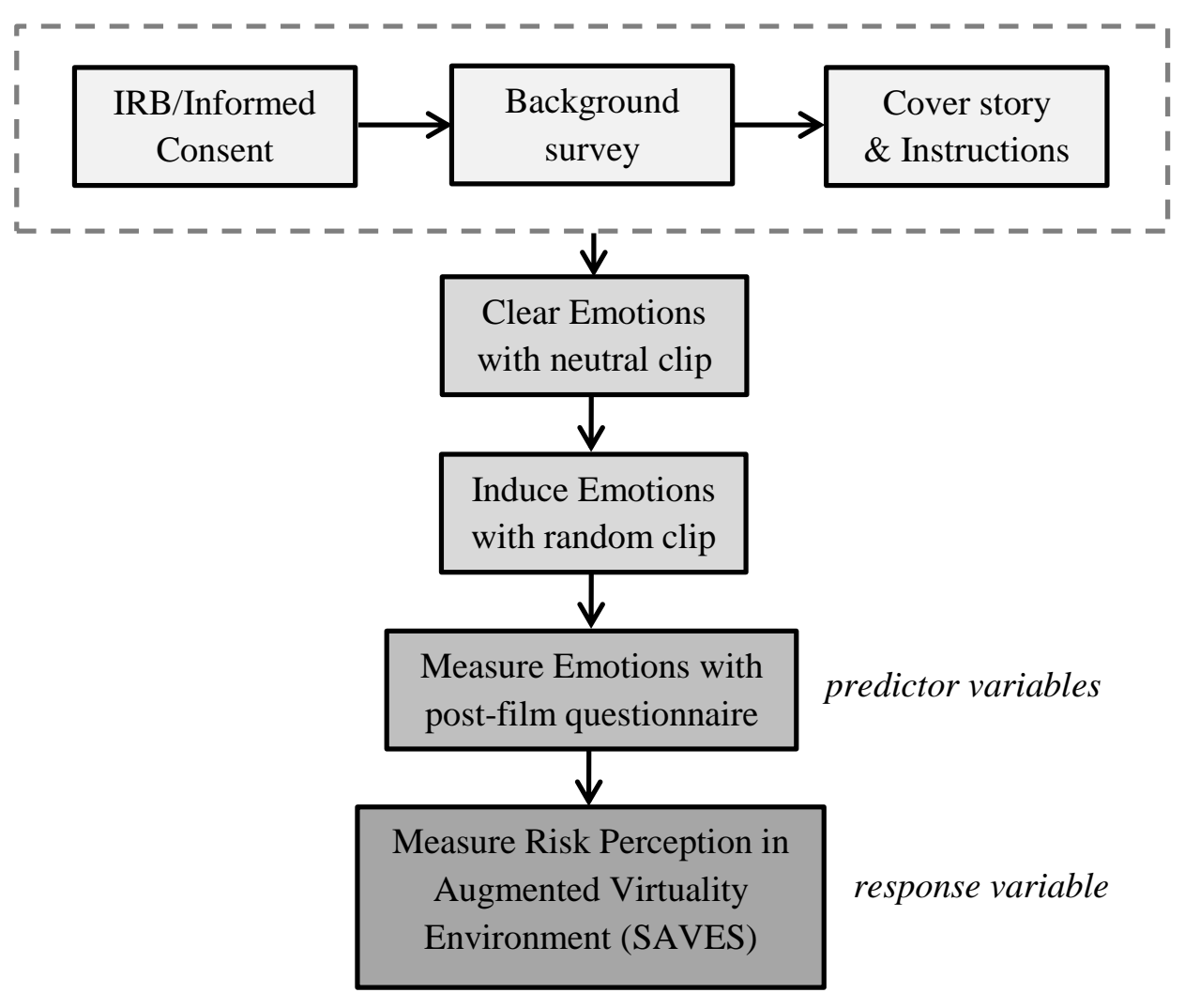

Figure 2 - Data collection methods

\section{Subject recruitment}

Our sample consisted of 68 participants, 58 University of Colorado at Boulder Civil, Environmental, Architectural, and Engineering undergraduates and 11 graduate students. Consistent with the department demographics, $77 \%$ were male and the mean age was 23 years with a standard deviation of 4.64 years. Participation was voluntary, and those who accepted were willing to follow instructions without reservation. Participants were not compensated for participating in the study.

In an attempt to control external biases, we decided to use students as the subjects for this experiment because we believe that they are less likely than workers to be biased by their past experiences and anticipatory emotions when presented with specific occupational environments. 
For example, a veteran welder may experience no anticipatory emotion such as fear when presented with a situation where a torch is very close to an acetylene tank because they may not have observed an injury in many years. However, someone less familiar with the task may experience an anticipatory emotion such as fear or anxiety, rightfully, when facing the same situation and, thus, perceive the risk more accurately. We believe that the absence of these experience biases in anticipatory emotions among students allowed us to measure more accurately the impact of the induced emotions on their risk perception.

\section{Laboratory environment and experimental protocol}

Two weeks before the actual experiment, participants were split between four groups consisting of 16, 20, 20, and 12 subjects. The experiment was thus conducted on four different sessions that took place over the course of three days. Each session was one hour and a half in length and was held in a computer lab that had been reserved for the occasion. Having small groups allowed research coordinators to communicate instructions efficiently, to make sure every participant was following them carefully, and limited unwanted interaction between subjects. When conducting psychological experiments, it is essential to have a properly controlled laboratory. This is especially true when investigating emotions because emotional states can be influenced by comfort level, interaction with other participants, and other distractions. Consequently, we took great care to set up an ideal laboratory environment consistent with recommendations from past literature. Each participant was sitting on a comfortable chair, in front of a powerful computer (8GB of RAM, $3.2 \mathrm{GHz}$ ) featuring a 27 inches $1920 \times 1080$ pixel monitor. The room was wellventilated, temperature-controlled, and moderately lit. There were no other activities being conducted in the proximate space. Each student had their own set of headphones and the ability 
to adjust volume to their comfort. There were 4 students on each row of the lab, which allowed a distance of about 3.5 feet on each side between students. The computer towers served as separations between the monitors so that it was impossible for a participant to see their neighbors' monitors. Each session consisted in 8 different steps (fig. 3).

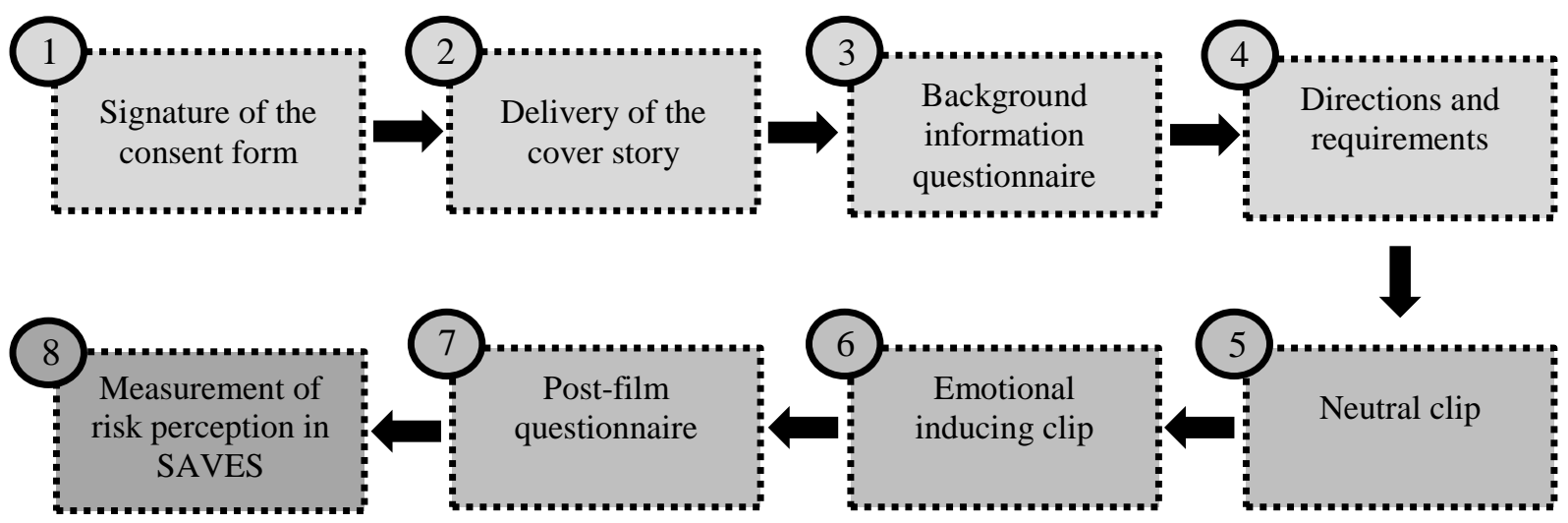

Figure 3 - Critical steps of the experiment

\section{Introductory activities and experimental set-up}

It was important that the subjects were unaware of the project objectives to avoid awareness biases (Harmon-Jones et al. 2007). Furthermore, because participants in a research study are often curious and suspicious, the context of the experiment must make sense to them, or their attention will be lost. We provided students with plausible explanations for purpose of their activities and tasks, thereby creating a simple but convincing cover story that followed HarmonJones et al.'s (2007) guidelines and complied with our Internal Review Board (IRB) approval. We explained that the sole purpose of the study was to increase subjects' hazard recognition skills using an augmented virtual environment (SAVES) and to test the effectiveness of SAVES as a training tool. To explain the emotional inducement, we claimed that an unrelated miniexperiment was being conducted in order to help a colleague from the Psychology Department, which involved viewing two brief video clips and completing a questionnaire. We did not debrief the participants about the true purpose of the experiment until all groups were done with the 
laboratory sessions. The subterfuge of the "multiple study" is a very common way to elaborate a cover story in social science experiments (Wilson et al. 2010). Once the cover story was provided, we administered a background survey that requested basic demographic information from each participant such as age, sex, experience, and others. We were very cautious with our appearance and behavior during the experiment. The role of each coordinator was previously determined and practiced so that we behaved consistently with each other and conveyed a sense of confidence while delivering the cover story and providing instructions. Our clothing was ordinary to avoid subconscious influences on participants' behaviors (Bargh and Ferguson 2000, Simon et al. 1997). We also treated each participant in the same neutral manner, and avoided being too friendly and chatty so that participants were in a relatively neutral emotional state at the beginning of the session. Because of the sensitive nature of our study, we applied for and received approval from the University of Colorado's Institutional Review Board (Protocol \#: 120640). Upon arrival in the experiment room, participants were asked to sign a consent form to participate in a research study. Before leaving the room at the end of the experiment, they were given a copy of the form.

\section{Inducing and measuring emotions (independent variables)}

Numerous techniques have been used by researchers to induce emotions. Some examples include essay writing on emotional memories (Schaefer and Philippot 2005), mental role-playing tasks (Schaefer et al. 2003), emotional statement reading (Velten 1968), imaginal mood treatment (Boyle 1984), facial and respiratory feedback (Philippot et al. 2002, Matsumoto 1987), unexpected gifts (Isen and Patrick 1983), exposure to images and music (Lynn et al. 2012, Schaefer et al. 2009), or movie excerpt viewing (Rottenberg et al. 2007). We selected movie 
clips because the technique possesses many of the strengths of the other methods and literature provided very strong support. Exposure to movie extracts has become a standard emotioneliciting technique, used in various fields such as social and cognitive psychology, neuroscience, medical imaging, marketing, and persuasion (Verduyn et al. 2012, Karama et al. 2011, DroitVolet et al. 2011, Griskevicius et al. 2009, Schaefer et al. 2006, Philippot et al. 2003, Yuen and Lee 2003, Ekman 1984). Karama et al. (2011) provided clinical support for our selection by demonstrating, using Magnetic Resonance Imagery, that emotional film clip viewing led to strong specific brain area activation. Using video clips also minimized ethical and practical challenges because it is time efficient, has a high degree of ecological validity, and allows a great deal of standardization that promotes internal validity and cross-comparison with other studies (Gross and Levenson 1995). Movie extracts are also less likely to be perceived by participants as deceptive or manipulative, compared with other emotion induction techniques (Ross et al. 1975) and, because watching commercial film clips is generally perceived as pleasant, participants' interest (i.e., attentional capture) is usually very high (Rottenberg et al. 2007). It should be noted that the fair use of short copyrighted movie extracts for teaching or research purpose is not an infringement of copyright, as outlined under Title 17, Section 107 of U.S. Copyright Law. The Code of Best Practices in Fair Use for Scholarly Research in Communication states that the use is legal and considered fair if researchers do not use more of the material than they need to accomplish their goals.

\section{Selection of the specific movie clips}

An extensive body of literature has proposed, tested, and validated movie excerpt batteries for eliciting various emotional states (e.g., Schaefer et al. 2010, Rottenberg et al. 2007, Von Leupoldt et al. 2007). Because movies are deeply anchored in the norms and the culture of their 
time, we only picked film clips belonging to the most recent and updated validated databases at our disposal. However, even these recent studies offer quite old movies mainly from the 1990s and 1980s. We selected from these clips because it was crucial to use only material that had been previously validated by the literature in order to further increase the internal validity of our experiment. We aimed to elicit basic emotions. There are two main schools of thoughts with respect to which emotions are fundamental. Izard $(1972 ; 1971)$ claims that the following 10 emotions can be considered as basic: interest, joy, surprise, distress, anger, disgust, contempt, fear, shame, and guilt. On the other hand, Ekman (1992a; 1982) claims that there are only six fundamental emotions: surprise, fear, happiness, sadness, anger and disgust. Despite these equivocal theories, there is strong agreement that anger, fear, sadness, and happiness qualify as basic (Clore et al. 1994). Therefore, we created six movie clips, one for each selected basic emotion and two neutral clips that are noted in previous literature (see Table 1). The first neutral clip was used to neutralize the emotional states of all participants when starting the experiment because, according to Rottenberg et al. (2007) using a neutral clip is preferable than a resting state. The second neutral clip was used to create a control group from a randomly selected sample of participants. Movie clips were created from the full-length movies, in high definition (1080 x 720 pixels, 30 frames per second) and audio quality (126 kbps, $44 \mathrm{kHz}$, stereo) using Camtasia Studio 8. It should be noted that our primary goal for using these clips was to obtain variability in participants' emotional states following exposure in order to observe differences between positive and negative groups. We did not aim in testing the effectiveness of the clips in eliciting their targeted emotions. 
Table 1 - Selected emotions and movie clips used to elicit specific emotions

\begin{tabular}{|l|l|c|l|}
\hline \multicolumn{1}{|c|}{ Target Emotion } & \multicolumn{1}{c|}{ Movie Clip } & Duration & \multicolumn{1}{c|}{ Origin } \\
\hline Neutral (baseline) & Denali National Park & $3: 40$ & $\begin{array}{l}\text { Rottenberg et al.'s } \\
\text { (2007) }\end{array}$ \\
\hline Neutral (control) & Gabon: the Last Eden & $3: 06$ & $\begin{array}{l}\text { Rottenberg et al.'s } \\
\text { (2007) }\end{array}$ \\
\hline Anger & Schindler's List & $2: 39$ & Schaefer et al.'s (2010) \\
\hline Sadness & The Champ & $3: 21$ & Hewig et al. (2005) \\
\hline Fear & The Silence of the Lambs & $4: 17$ & Rottenberg et al. (2007) \\
\hline Happiness & Whose Line is it Anyway? & $2: 13$ & Rottenberg et al. (2007) \\
\hline
\end{tabular}

\section{Residence time of induced emotions}

We took into account the fact that emotions change and evolve rapidly over time (Verduyn et al. 2011, Rottenberg et al. 2007) when measuring risk perception after the emotional manipulation. It has been demonstrated that a typical emotional residence time, the period between the onset point and the moment the emotion is no longer felt lasts from only a few seconds to a couple of hours or days (Gilboa and Revelle 1994; Fitness and Fletcher 1993). Recent researchers have collected more precise empirical data that considerably enhanced our understanding of the duration of emotional episodes (see Table 2). As one can see, residence time for various emotions ranges from 11 to 26 minutes, with a median over 15 minutes. Therefore, we chose to measure risk perception within the 15 minutes following the end of the viewing of the second movie clip, which we consider to be a conservative decision (see fig. 4). To further the rigor of our study, we were very careful to only select and use the highest ranked and most intense clips available in the literature because such clips are known to increase residence time (Verduyn et al. 2009b, Schimmack 2003, Sonnemans and Frijda 1995). 
Table 2- Residence time for specific emotions

\begin{tabular}{|l|c|c|c|}
\hline Emotion & Residence time (min) & Number of participants & Study \\
\hline Fear & 16 & 110 & \multirow{2}{*}{ Verduyn et al. 2009b } \\
\hline \multirow{3}{*}{ Anger } & 22 & 110 & \\
\cline { 2 - 4 } & 11 & 50 & Verduyn et al. 2011 \\
\cline { 2 - 4 } & 12 & 344 & \\
\hline \multirow{3}{*}{ Joy } & 26 & 110 & Verduyn et al. 2009b \\
\cline { 2 - 4 } & 19 & 50 & Verduyn et al. 2011 \\
\cline { 2 - 4 } & 12 & 344 & Verduyn et al. 2009b et al. 2011 \\
\hline \multirow{2}{*}{ Sadness } & 20 & 50 & \\
\cline { 2 - 4 } & 15 & 344 & \\
\hline
\end{tabular}

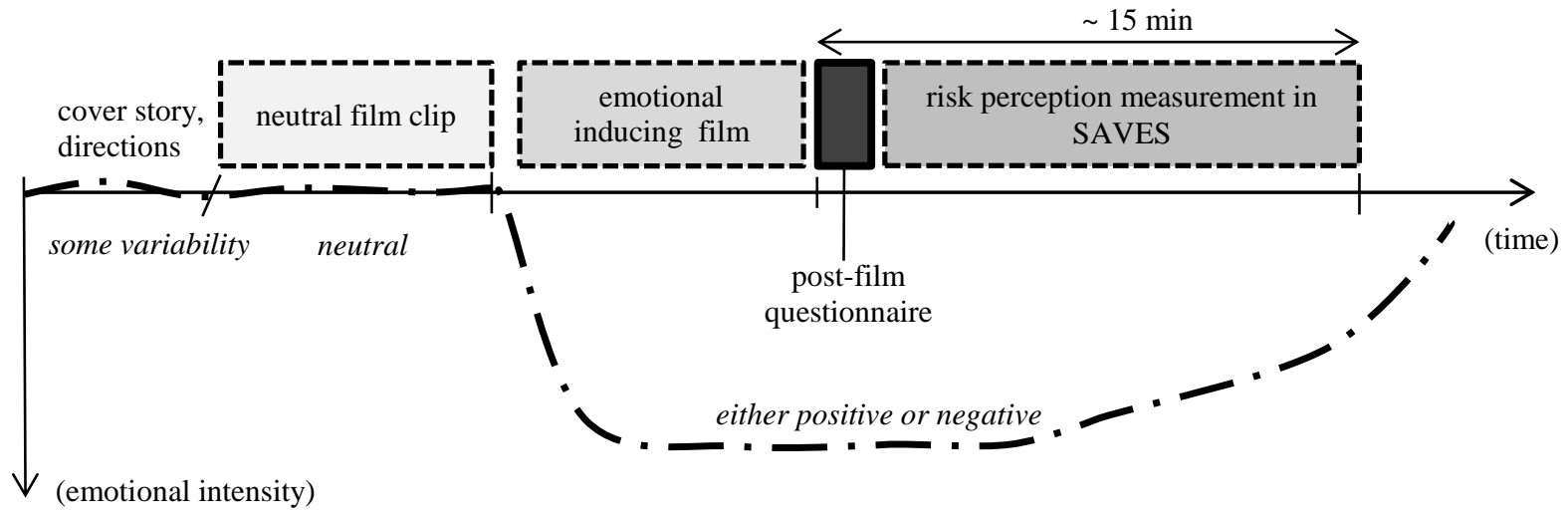

Figure 4 - Duration of emotional episode through the experiment

\section{Measuring emotional state with a post-film questionnaire}

As indicated, all participants started the experiment by watching a neutral clip. Following this clip, participants were randomly assigned an emotion eliciting clip or, for the randomly selected control group, a second neutral clip. We measured participants' emotional states after the second movie-clip using Rottenberg et al.'s (2007) post-film questionnaire. The different emotion terms used in this questionnaire include a number of very important discrete, positively and negatively valenced emotions that are a subset of the basic emotions. On this questionnaire (see appendix), participants rated their emotions on 9-point Likert scale. This informed us about the type of emotion they experienced and the intensity of their emotional experiences themselves. 
Participants accessed the videos via a steaming service on the course webpage. The six videos were uploaded by a research coordinator right before each session began so it was impossible for students to watch the videos in advance. The videos were named 0 to 5 , so participants could not get any information about the film clips when opening the files.

\section{Measuring risk perception using a standardized data collection strategy embedded in a highly realistic immersive virtual construction environment}

We had access to a high fidelity augmented virtual environment of an industrial construction site that was created for past research (Hallowell et al. 2013). This system, known as SAVES, has an integrated questionnaire that was used to quantify risk perception as a subject navigates the virtual environment and encounters embedded hazards. The SAVES system immerses participants in a highly realistic worksite that was created using an actual building information model and over 200 photographs of representative worksites. We were confident in using this environment because Slater (2009) showed that people can respond realistically to immersive virtual environments such as SAVES.

With the exception of measuring risk perception on an actual construction site, we believe that immersion in SAVES was the best method for simulating actual construction risks in a highly realistic fashion. It was impractical and potentially unsafe to manipulate participants' emotions and measure their risk perception on-site. Alternatively, SAVES allows students to experience situations that are unsafe without being exposed to actual risk. Additionally, the laboratory environment was preferred over a construction site because the laboratory allows an optimal control and, therefore, a reduction of non-measurable interferences that could modify participants' emotions. 
As opposed to augmented reality, which adds computer-generated information to a real environment, SAVES can be qualified of being an augmented virtuality tool, in that it incorporates real pictures into a virtual environment. As users encounter a hazard in SAVES, a high definition still picture of the hazard emerges. Hazards and their associated pictures in SAVES depict construction situations that vary in dangerousness, ranging from very common to extremely hazardous. When moving about the virtual environment, participants come across the different hazards and their pictures randomly.

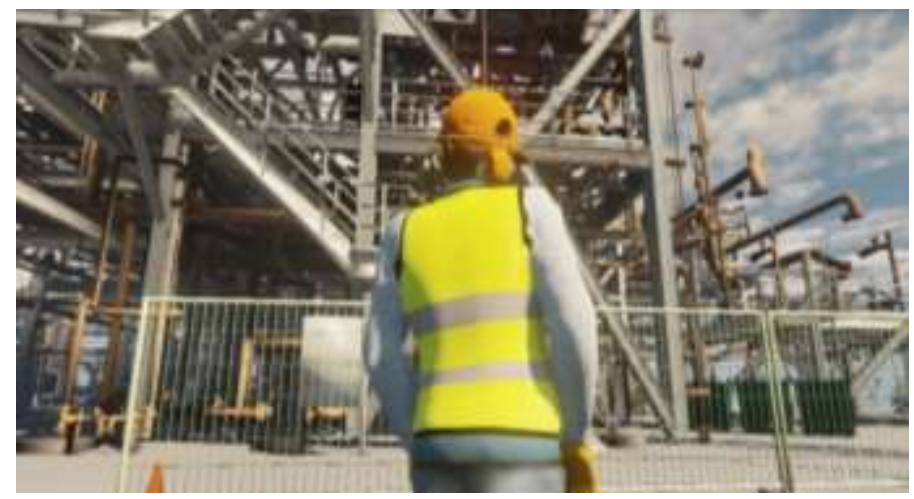

Figure 5 - Sample SAVES environment

\section{Measuring risk perception in SAVES}

As subjects encountered hazards, we asked them to fill out a paper-based risk perception questionnaire for the first five hazards they encountered as long as it was within the first 15minutes.The questionnaire featured 5 risk perception tables. After 15-minutes, the questionnaire was collected even if the 5 tables were not completed because the emotional inducement could no longer be assumed to be effective. 
As previously indicated, risk perception is defined as the subjective judgment that one makes about the frequency and severity of specific risks (Slovic et al. 1980). Typically, these values are obtained by questioning individuals about different risk scenarios and aggregating the data. In order to measure risk objectively and to allow comparison between participants, we used a method of quantifying risk designed by Baradan and Usmen (2006). In this approach, safety risk is defined in terms of frequency (incident per worker-hours) and relative severity level (impact to the worker). The relationship between unit risk, frequency, and severity is shown by the following equation:

\section{Unit Risk $($ S/w-h $)=$ Frequency $($ incidents/w-h $) \times$ Severity $($ S/incident $)$}

When providing estimates of frequencies and severities associated with the hazards they encountered, participants were asked not to respond based on what they felt or believed but solely on what they thought would really happen in reality in the same exact situation depicted by the picture. Following OSHA definitions, participants were given the following injury types definitions that they could access at any time during the experiment via provided handouts:

- First aid: any treatment of minor scratches, cuts, burns, splinters, etc. The worker should be able to return to work following the treatment.

- Medical case: any work-related injury or illness requiring medical care or treatment beyond first aid. The worker should be able to return to their regular work and function in normal capacity.

- Lost work time: any work-related injury or illness that prevents the worker from returning to work the following day.

- Permanent disablement or fatality: any work-related injury or illness that results in permanent disablement or death. 
- For each picture encountered, we asked each participant to indicate the frequency with which they would expect to be injured for each severity level. A representative sample of the questionnaire is provided in Table 3. These data for five pictures were obtained for each participant, then the data were aggregated to produce a relative risk perception score for each individual.

\section{Table 3 - Blank Risk Perception Table}

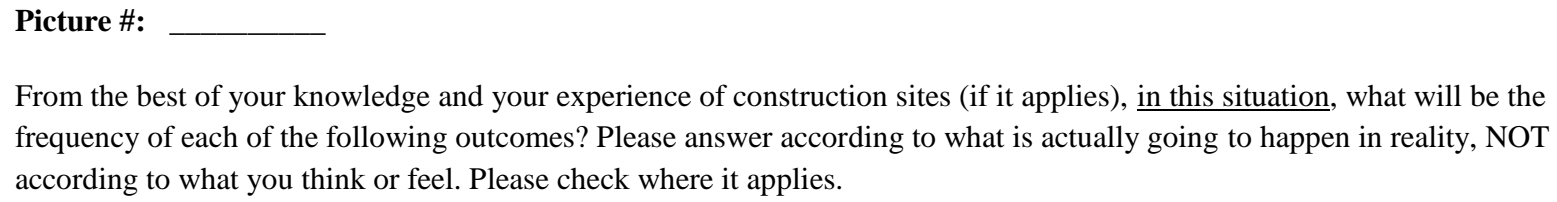

\begin{tabular}{|l|l|l|l|l|}
\hline Injury type & Once every week & Once every month & Once every year & Once every ten years \\
\hline First aid & & & & \\
\hline Medical case & & & & \\
\hline Lost work time & & & & \\
\hline $\begin{array}{l}\text { Permanent disablement } \\
\text { or fatality }\end{array}$ & & & \\
\hline
\end{tabular}

\section{Quantifying frequency and severity}

As shown in Table 5, participants indicated the approximate frequency with which each injury severity level may be experienced for each picture. We informed the students that the assumption was that one worker week was equivalent to 40 worker-hours, 167 worker-hours per month, and 2,000 worker-hours per year. To compute a severity score for each severity level we used the severity scores defined by Hallowell and Gambatese (2008). These scores, which can be compared and summed, correspond to various injury severity levels, namely: (1) minor first aid, (2) major first aid, (3) lost work time, (4) medical case, (5) permanent disablement, and (6) fatality, and are based upon the impact of the outcome to the worker. To simplify we combined minor and major first aid into the lowest severity level and permanent disablement and fatality 
into the highest severity level. Consequently, our first aid severity score was $2^{5.5}=45.26$ and our permanent disablement/fatality severity score was $(1,024+26,214) / 2=13,619$.

Table 4 - Simplified severity scale

\begin{tabular}{|c|c|}
\hline Outcome to the worker & $\begin{array}{c}\text { Relative } \\
\text { Severity }\end{array}$ \\
\hline First aid & 45.255 \\
\hline Lost work time & 128 \\
\hline Medical case & 256 \\
\hline $\begin{array}{c}\text { Permanent disablement } \\
\text { or fatality }\end{array}$ & 13,619 \\
\hline
\end{tabular}

Obtaining a score using a risk perception table

When computing a participant's risk aggregate perception score we summed the risk perceived at each severity level. To illustrate the computation, we provide an example in Tables 5 and 6 . This participant's perceived risk was calculated as the sum of the unit risks corresponding to the checked boxes. In this case, the participant's risk perception score would be calculated as $1.13+$ $0.77+1.54+6.81=10.25$. In total, each participant filled 5 risk perception tables, getting 5 risk perception scores. We then computed an overall risk perception score for each participant, as will be explained in the analysis section.

Table 5 - Risk perception table.

\begin{tabular}{|l|c|c|c|c|}
\hline & $\begin{array}{c}\text { once a } \\
\text { week }\end{array}$ & $\begin{array}{c}\text { once a } \\
\text { month }\end{array}$ & $\begin{array}{c}\text { once a } \\
\text { year }\end{array}$ & $\begin{array}{c}\text { once every } \\
\text { ten years }\end{array}$ \\
\hline First aid & $\mathrm{X}$ & & & \\
\hline medical case & & $\mathrm{X}$ & & \\
\hline lost work time & & $\mathrm{X}$ & & \\
\hline $\begin{array}{l}\text { permanent } \\
\text { disablement or } \\
\text { fatality }\end{array}$ & & & $\mathrm{X}$ & \\
\hline
\end{tabular}


Table 6 - Unit risks showed for each combination of severity and frequency of the risk perception table

\begin{tabular}{|l|c|c|c|c|}
\hline \multicolumn{1}{|c|}{ Frequency } & $\begin{array}{c}\text { once a } \\
\text { week } \\
1 /(40 \mathrm{w}- \\
\mathrm{h})\end{array}$ & $\begin{array}{c}\text { once a } \\
\text { month } \\
1 /(166.7 \mathrm{w}- \\
\mathrm{h})\end{array}$ & $\begin{array}{c}\text { once a year } \\
1 /(2,000 \mathrm{w}-\mathrm{h})\end{array}$ & $\begin{array}{c}\text { once every ten } \\
\text { years } \\
1 /(20,000 \mathrm{w}-\mathrm{h})\end{array}$ \\
\hline $\begin{array}{l}\text { 1st aid injury } \\
(45.255)\end{array}$ & 1.13 & 0.27 & $2.26 \times 10^{-2}$ & $2.26 \times 10^{-3}$ \\
\hline medical case (128) & 3.20 & 0.77 & $6.40 \times 10^{-2}$ & $6.40 \times 10^{-3}$ \\
\hline loss work time (256) & 6.40 & 1.54 & $1.28 \times 10^{-1}$ & $1.28 \times 10^{-2}$ \\
\hline $\begin{array}{l}\text { permanent } \\
\text { disablement or } \\
\text { fatality (13.619) }\end{array}$ & 340.5 & 81.7 & 6.81 & $6.81 \times 10^{-1}$ \\
\hline
\end{tabular}

In total, each participant was asked to fill 5 risk perception tables, getting 5 risk perception scores. We then computed an overall risk perception score for each participant, as will be explained in the analysis section.

\section{DATA ANALYSIS}

Our data analysis involved reducing the risk perception data to one score by aggregating the data, clustering emotions data and reducing the dimensions of the dataset to principal emotions using principal components analysis, and measuring differences in risk perception scores among participants with specific emotional states. This process is illustrated in Figure 6.

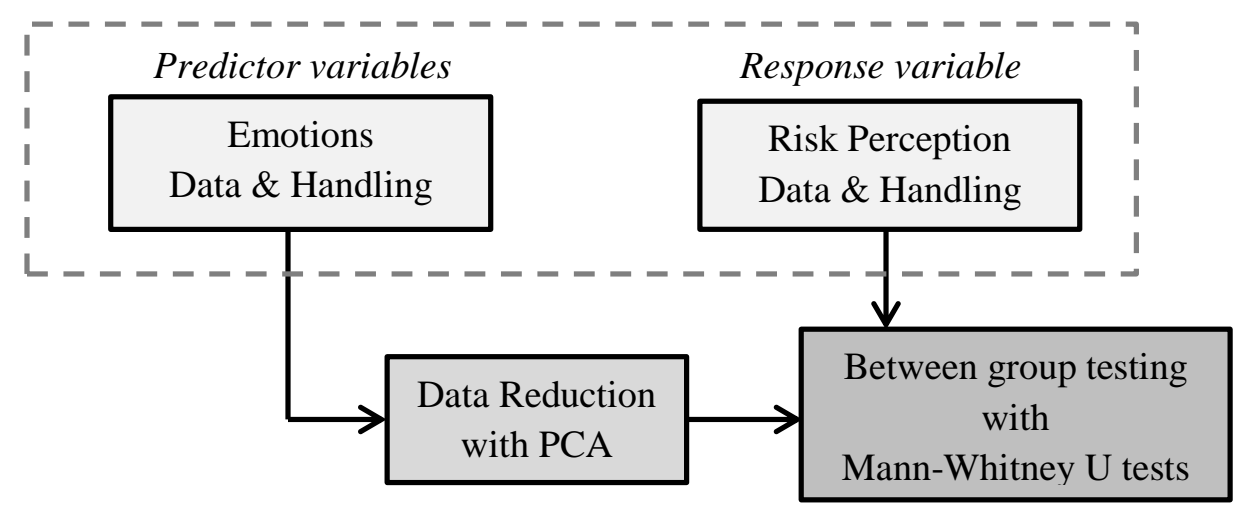

Figure 6 - Emotions data and handling 


\section{Clustering emotions using Principal Component Analysis}

In order to model the relationship between subjects' emotions (independent variables) and their risk perception (dependent variable), we reduced the dimension of our data using Principal Component Analysis (PCA). PCA is a well-known dimension reduction method which allows the user to describe the variability in a data set by using only a smaller set of variables (Joliffe 1986). Specifically, we used PCA to identify highly correlated emotions and group them together as new independent variables, thus making the interpretation of the relationship between emotions and risk perception more efficient. One of the advantages of PCA is that, while dramatically reducing the dimensionality of our data set, the method retains almost all of the variation present in the original variables (Massey 1965).

Although PCA is primarily intended for continuous data, Muthen and Kaplan (1985) showed that PCA performs quite well with ordered categorical variables such as Likert scales, especially for data reduction and clustering. More precisely, Muthen (2004) found that it is possible to find true parameter values in PCA with Likert scale data. We only used PCA as a way to identify groups among our independent variables. We did not perform any statistical test using the loading scores provided by PCA for each variable on each factor because, to obtain reliable results, a very large sample is required.

As noted by Comrey and Lee (2002) and Tabachnick and Fidell (2001), a minimum of 10 observations per independent variable is an absolute minimum to use PCA. Thus, we removed 7 emotions from our initial set of 18 emotions. The removed emotions were anger (only 9 observations), love (4), pride (4), shame (4), contempt (1), guilt (0), and embarrassment (0). The remaining emotions were amusement (25 observations), anxiety (21), confusion (12), disgust (13), fear (18), happiness (26), interest (49), joy (20), sadness (23), surprise (15), and 
unhappiness (19), that is 11 emotions. According to Hatcher (1994), to obtain strong PCA groupings, the number of subjects should be greater than five times the number of variables being analyzed. With our 11 independent variables, and a number of subjects of 69 people, we exceed this requirement $(69>55)$.

\section{First iteration}

We used SPSS 21.0 to perform the PCA. As recommended by Tabachnick and Fidell (2007), we started by using an oblique rotation method. We used the direct-oblimin technique, which is the most commonly used of the oblique rotation methods (Kim and Mueller 1978). In the correlation matrix, no correlation coefficient was greater than $.879(\mathrm{p}<0.001)$. The determinant of the correlation matrix was equal to $0.007(0.007>>0.00001)$. For these reasons, we could tell that we did not have singularity or multicollinearity issues (Field et al. 2012). The Kaiser-Meyer-Oklin (KMO) test of global sampling adequacy $(0.764>0.7)$ and the Bartlett's test of sphericity $(\mathrm{p}<0.001)$ both passed. In addition, following the recommendations of Norman and Streiner (2007), two variables (confusion and surprise) were removed because they had individual sampling adequacy scores less than 0.7 (0.367 and 0.391 , respectively).

\section{Second iteration}

After the removal of confusion and surprise emotions, the determinant of the correlation matrix improved from 0.007 to 0.01 . Additionally, the KMO test for sampling adequacy $(0.801>0.7)$ and the Bartlett's test of sphericity $(\mathrm{p}<0.001)$ passed with an even better global sampling adequacy score $(0.801>0.764)$. This time, no individual sampling adequacy score was less than 0.7. The eigenvalue-one criterion for factor extraction gave us two factors. The two factors were 
correlated, exceeding the 0.32 threshold provided by Tabachnick and Fidell (2007) with a Pearson coefficient of 0.407 , which was expected and normal given the oblique rotation technique used. The output in SPSS for an oblique rotation method includes both a pattern and a structure matrix. Because we are only using PCA to cluster our emotions into groups, what we were interested in was the pattern matrix, as shown in Table 7, because it represents the loadings of the factors on each variable.

Table 7 - Pattern matrix from iteration 2

\begin{tabular}{|c|c|c|}
\hline \multirow{2}{*}{ Emotion } & \multicolumn{2}{|c|}{ Component } \\
\cline { 2 - 3 } & 1 & 2 \\
\hline Amusement & -.859 & .095 \\
\hline Joy & -.835 & -.076 \\
\hline Happiness & -.821 & -.163 \\
\hline Interest & -.748 & .141 \\
\hline Sadness & .522 & .220 \\
\hline Fear & -.024 & .852 \\
\hline Anxiety & .029 & .814 \\
\hline Disgust & -.048 & .794 \\
\hline Unhappiness & .377 & .481 \\
\hline
\end{tabular}

According to Kline (2002) and Bryant and Yarnold (1995), in a simple structure, each factor should have a few loadings being close to zero (this is between -0.1 and +0.1 , according to Gorsuch 1983). Furthermore, loadings of 0.3 or higher can be considered at least salient (Kline 2002). We can see from our pattern matrix that under these definitions, Happiness $(0.821$, 0.163), Interest $(0.748,0.141)$, Sadness $(0.522,0.220)$, and Unhappiness $(0.377,0.481)$ are considered complex variables (they load on both factors). Also, from a construct's standpoint, it does not quite make sense to have sadness grouped with amusement, joy, and happiness, even though the signs are opposite.

In addition to the complex structure of our two-factor model and the confounding grouping, the model only explained about $63 \%$ of the original variance in our data set, as shown in Table 8 . 
Even though it is impossible to come up with a model that accounts for $100 \%$ of the variance, $63 \%$ can be considered a rather moderate value because the majority of literature recommends targeting $70 \%$. For all these reasons, we decided to re-run PCA, forcing the extraction of three factors in SPSS.

Table 8 - Total Variance Explained from iteration 2

\begin{tabular}{|c|c|c|c|c|c|c|c|}
\hline \multirow[b]{2}{*}{ Component } & \multicolumn{3}{|c|}{ Initial Eigenvalues } & \multicolumn{3}{|c|}{$\begin{array}{c}\text { Extraction Sums of Squared } \\
\text { Loadings }\end{array}$} & \multirow{2}{*}{$\begin{array}{c}\text { Rotation } \\
\text { Sums of } \\
\text { Squared } \\
\text { Loadings } \\
\text { Total }\end{array}$} \\
\hline & Total & $\begin{array}{c}\% \text { of } \\
\text { Variance }\end{array}$ & $\begin{array}{c}\text { Cumulative } \\
\%\end{array}$ & Total & $\begin{array}{c}\% \text { of } \\
\text { Variance }\end{array}$ & $\begin{array}{c}\text { Cumulative } \\
\%\end{array}$ & \\
\hline 1 & 4.254 & 47.262 & 47.262 & 4.254 & 47.262 & 47.262 & 3.700 \\
\hline 2 & 1.415 & 15.725 & 62.987 & 1.415 & 15.725 & 62.987 & 3.091 \\
\hline 3 & .868 & 9.643 & 72.630 & & & & \\
\hline 4 & .745 & 8.277 & 80.907 & & & & \\
\hline 5 & .541 & 6.016 & 86.923 & & & & \\
\hline 6 & .420 & 4.669 & 91.593 & & & & \\
\hline 7 & .360 & 4.005 & 95.598 & & & & \\
\hline 8 & .287 & 3.188 & 98.786 & & & & \\
\hline 9 & .109 & 1.214 & 100.000 & & & & \\
\hline
\end{tabular}

\section{Third iteration}

Following the same protocol described in the previous iterations, our new three-factor model accounted for almost $73 \%$ (72.643) of the variance in the initial data set (see Table 9). Also, we found the results easier to interpret. The variables which load on factor 1 (joy, happiness, and amusement) measure the same construct which is a positive valence. We drew similar conclusions for factor 2 (fear, anxiety, disgust) and factor 3 (sadness and unhappiness). These findings are not only statistically significant but also are supported by theories in past literature. According to all the definitions and criteria previously mentioned, we had a close to perfect simple structure on this pattern matrix. We also verified that our three components were still correlated. Again, this was normal and expected due to the oblique rotation technique used. 
Table 9 - Total Variance Explained from iteration 3

\begin{tabular}{|c|c|c|c|c|c|c|c|}
\hline \multirow[t]{2}{*}{ Component } & \multicolumn{3}{|c|}{ Initial Eigenvalues } & \multicolumn{3}{|c|}{$\begin{array}{l}\text { Extraction Sums of Squared } \\
\text { Loadings }\end{array}$} & \multirow{2}{*}{$\begin{array}{c}\text { Rotation } \\
\text { Sums of } \\
\text { Squared } \\
\text { Loadings } \\
\text { Total }\end{array}$} \\
\hline & Total & $\begin{array}{c}\% \text { of } \\
\text { Variance }\end{array}$ & $\begin{array}{c}\text { Cumulative } \\
\%\end{array}$ & Total & $\begin{array}{c}\% \text { of } \\
\text { Variance }\end{array}$ & $\begin{array}{c}\text { Cumulative } \\
\%\end{array}$ & \\
\hline 1 & 4.254 & 47.262 & 47.262 & 4.254 & 47.262 & 47.262 & 3.700 \\
\hline 2 & 1.415 & 15.725 & 62.987 & 1.415 & 15.725 & 62.987 & 3.091 \\
\hline 3 & .868 & 9.643 & 72.630 & .868 & 9.643 & 72.630 & 2.635 \\
\hline 4 & .745 & 8.277 & 80.907 & & & & \\
\hline 5 & .541 & 6.016 & 86.923 & & & & \\
\hline 6 & .420 & 4.669 & 91.593 & & & & \\
\hline 7 & .360 & 4.005 & 95.598 & & & & \\
\hline 8 & .287 & 3.188 & 98.786 & & & & \\
\hline 9 & .109 & 1.214 & 100.000 & & & & \\
\hline
\end{tabular}

Table 10 - Pattern matrix from iteration 3

\begin{tabular}{|l|c|c|c|}
\hline \multirow{2}{*}{ Joy } & \multicolumn{3}{|c|}{ Component } \\
\cline { 2 - 4 } & 1 & 2 & 3 \\
\hline Happiness & -.891 & -.154 & .092 \\
\hline Amusement & -.828 & -.202 & -.009 \\
\hline Interest & -.807 & .084 & -.092 \\
\hline Fear & -.725 & .114 & -.032 \\
\hline Anxiety & .029 & .853 & -.007 \\
\hline Disgust & .041 & .792 & .065 \\
\hline Sadness & -.014 & .784 & .022 \\
\hline Unhappiness & .048 & -.092 & .917 \\
\hline
\end{tabular}

\section{Accepting the three-factor model from the third iteration}

Communalities account for the percent of variance in the independent variables explained by all the factors at the same time. Communalities may be considered as a measure of the reliability of 
the model (Garson, 2008). According to MacCallum, et al. (2001), communalities greater than 0.6 are synonym of a very accurate representation of the initial items by the components of the model, almost regardless of sample size. All our communalities were above this threshold of 0.6 (as shown in Table 11), except for interest (0.504), with a few being very high (0.849 for happiness, 0.829 for joy, 0.827 for sadness, and 0.783 for unhappiness), suggesting a very strong and accurate three-factor model.

Table 11 - Communalities from iteration 3

\begin{tabular}{|c|c|c|}
\hline & Initial & Extraction \\
\hline Amusement & 1.000 & .687 \\
Anxiety & 1.000 & .697 \\
Disgust & 1.000 & .620 \\
Fear & 1.000 & .741 \\
Happiness & 1.000 & .849 \\
Interest & 1.000 & .504 \\
Joy & 1.000 & .829 \\
Sadness & 1.000 & .827 \\
Unhappiness & 1.000 & .783 \\
\hline
\end{tabular}

\section{Interpretation of the factors}

According to Comrey and Lee (1992), a sample size between 50 and 100 subjects is not ideal. However, Preacher and MacCallum (2002) argued that as long as the communalities are high and the number of factors is small, researchers should not be concerned about small sample sizes. Similarly, according to Costello and Osborne (2005), high communalities without complex variables and several variables loading strongly on each factor is a sign of "strong data", no matter the sample size. Finally, Arrindell and van der Ende (1985) reported that a clear factor pattern could be obtained with sample sizes as low as 50 participants. In psychology, Boyle (1984), using PCA, also found that joy, surprise and interest loaded on a common factor. 
Traditionally in psychology, it also makes sense to group disgust, fear, and anxiety, as these three emotions are linked to the concept of anxiety disorders (Cisler et al. 2009). Even though only two emotions load on factor 3 , we believe that this third factor is valid as it makes sense from a theoretical standpoint.

\section{Risk Perception data and handling}

\section{Calculating relative risk perception scores}

Each participant completed a risk perception table for each of the five pictures encountered in the first 15 minutes following the randomly assigned movie clip. For each picture, a participant's perceived risk score was divided by the median of all risk perception scores for the same picture, yielding a relative risk perception score. A single risk perception score was computed for each participant by averaging their relative risk perception scores. Because students were free to move about the virtual environment and encountered pictures randomly, some pictures were encountered by less than three participants. Relative risk perception scores were not computed for these pictures. Nine participants were removed from the dataset because their responses yielded less than three risk perception scores and averaging less than three risk perception scores to find a global risk perception score is too dependent on the riskiness of the situation depicted in each picture. 


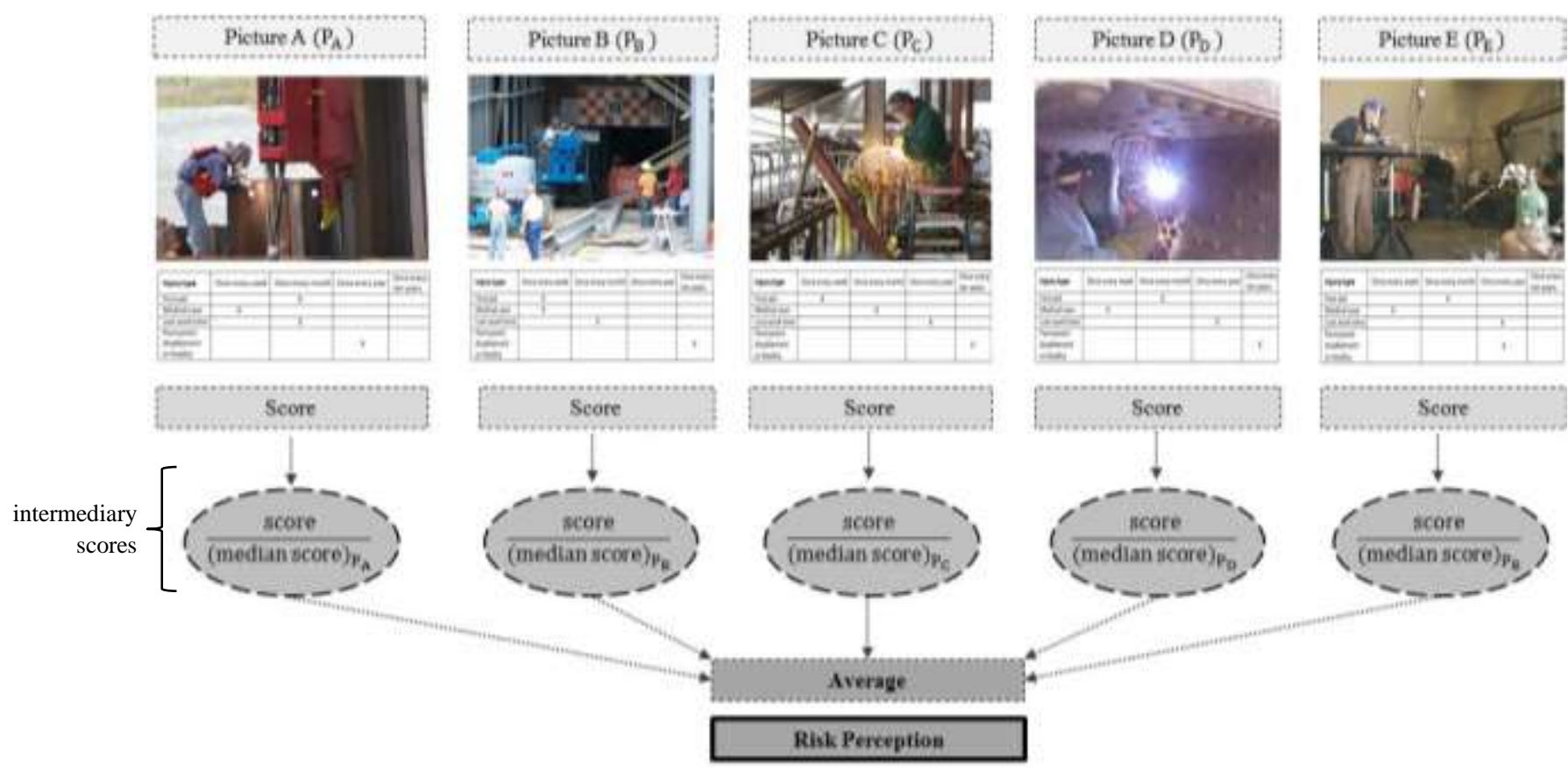

Figure 7 - Computing global Risk Perception scores

Testing for differences between group of emotions using multiple Mann-Whitney $U$ tests

\section{Splitting participants between factors}

Participants were split between the three emotional groups found by PCA, namely positive (amusement, happiness, interest, and joy), self-protective (fear, anxiety, disgust), and negative (sadness, unhappiness) groups, based on the sum of their scores for the emotions loadings on each specific group. For instance, in order for a participant to become a member of the selfprotective group, the sum of their scores for anxiety, disgust, and fear needed to equal or exceed $12(4+4+4)$, a level of 4 corresponding to "somewhat/some" on the post-film questionnaire Likert scales. For the positive and negative groups, the thresholds were calculated in the same manner to be 16 and 8 , respectively.

When the number of emotions taken into account was large (e.g., positive group), this way of measuring the belonging to a group could be inaccurate. For example, participant \#16 reported 
high levels of interest (6) and happiness (5), but did not report high levels of joy (0) and amusement (0). While reporting a fair amount of happiness (5 on a scale from 0 to 8 ), this participant was not considered a member of the positive group, because the sum of their scores for amusement, happiness, interest, and joy did not exceed 16. To address this issue, participant \#16 was manually added to the positive group, and after careful examination of the data, 15 participants in similar situations were also manually added to their appropriate groups. Additionally, some participants were classified in both the self-protective and the negative groups, exceeding both thresholds. As expected, some participants (10) did not belong to any group because they reported very small amount of every emotion. We created a neutral group for them.

Because Shapiro-Wilk's test showed that the risk perception independent variable data were not normally distributed ( $\mathrm{p}<0.05)$, as shown in (Table 12) we used Mann-Whitney U tests instead of independent-samples t-tests to determine if there were differences between emotion groups (positive, self-protective, negative, and neutral). Another advantage of the $\mathrm{U}$ test lies in its robustness to outliers because it transforms the data to ranks.

Table 12 - Tests of Normality

\begin{tabular}{|c|c|c|c|c|c|c|}
\hline \multirow{2}{*}{} & \multicolumn{3}{|c|}{ Kolmogorov-Smirnov } & \multicolumn{3}{c|}{ Shapiro-Wilk } \\
\cline { 2 - 7 } & Statistic & df & Sig. & Statistic & df & Sig. \\
\hline RP & 0.293 & 60 & $<0.001$ & 0.462 & 60 & $<0.001$ \\
\hline
\end{tabular}

\section{Results of the U tests}

Six $U$ tests were run on the dataset to measure differences between each factor. In every case, our independent variable was dichotomous and our dependent variable (relative risk perception score) was continuous. The assumptions of identical shapes of the distributions for the two 
groups were met in every case. A U test's null hypothesis is that the difference in the two population mean ranks is due to random sampling, assuming that the two populations have identical distributions. For reference, the descriptive statistics for the dataset are provided in Table 13.

Table 13 - Descriptive statistics

\begin{tabular}{|l|c|c|c|c|c|}
\hline \multicolumn{1}{|c|}{ Group } & Mean & N & Min. & Max. & Variance \\
\hline $\begin{array}{l}\text { Factor 1 } \\
\text { (positive) }\end{array}$ & 1.4352 & 25 & 0.67 & 3.76 & 0.692 \\
\hline $\begin{array}{l}\text { Factor 2 } \\
\text { (fear/anxiety/disgust) }\end{array}$ & 5.4981 & 16 & 0.48 & 32.62 & 62.114 \\
\hline $\begin{array}{l}\text { Factor 3 } \\
\text { (sadness/unhappiness) }\end{array}$ & 5.2843 & 21 & 0.52 & 32.62 & 26.769 \\
\hline $\begin{array}{l}\text { No group } \\
\text { (neutral) }\end{array}$ & 0.9370 & 10 & 0.07 & 2.24 & 0.393 \\
\hline
\end{tabular}

Strong statistically significant differences in Risk Perception scores were found between:

- The positive and the self-protective groups $(\mathrm{p}=.003)$ with a mean relative risk perception score of 1.44 for the positive group and 5.5 for the self-protective group,

- The positive and the negative groups $(\mathrm{p}=.009)$ with a mean relative risk perception score of 1.44 for the positive group and 5.3 for the negative group;

- The neutral and the self-protective group $(\mathrm{p}=.002)$ with a mean relative risk perception score of 0.94 for the neutral group and 5.5 for the self-protective group;

- The neutral and the negative groups $(\mathrm{p}=.003)$ with a mean relative risk perception score of 0.94 for the neutral group and 5.3 for the negative group. 
A U test was also run between the self-protective and the negative groups. Because some participants belonged to both groups and because the U test only works with independent groups, we removed participants belonging to both groups while running the test. The test was not statistically significant $(\mathrm{p}=0.347)$. Finally, a last $\mathrm{U}$ test was run between the positive and the neutral groups but again, no statistically significant difference was observed $(\mathrm{p}=0.742)$. These results are presented in Table 14.

Table 14 - Mann-Whitney U test results summary

\begin{tabular}{|c|c|c|c|c|}
\hline & Positive & Self-protective & Negative & Neutral \\
\hline Positive & 3 & 0.003 & 0.009 & NS \\
\hline Self-protective & 0.003 & S & NS & 0.002 \\
\hline Negative & 0.009 & NS & S & 0.003 \\
\hline Neutral & NS & 0.002 & 0.003 & $\infty$ \\
\hline
\end{tabular}

NS = Not Significant

\section{CONCLUSIONS, CONTRIBUTIONS, AND RECOMMENDATIONS}

Our results are consistent with theories of affect heuristic for general risk perception. This suggests that events associated with negative affect would be perceived as more risky (Keller et al. 2006, Slovic et al. 2004). Also, we found anxious, fearful, and disgusted subjects to have the highest relative risk perception, which is in accordance with previous findings showing that emotions are used by individuals as a source of information about the riskiness of their environment (Johnson and Tversky 1983) and that specific emotions such as anxiety and fear lead to the activation of self-protective processes (Öhman and Mineka 2001). Even though no statistical difference was found between the self-protective and the negative groups and both had high relative risk perception scores, it is to be noted that sad and unhappy subjects (negative group) had a lower relative risk perception than anxious, fearful, and disgusted subjects (self- 
protective group), which could correspond to previous evidence showing that only those individuals who are clinically moderately depressed have a relatively accurate assessment of the risks they face (Taylor and Brown 1988).

If, based on our findings, we assume that risk perception is inversely correlated to risk-taking, our results can be extrapolated to corroborate the findings which showed that negative emotions were linked to risk aversion (e.g., Yuen and Lee 2003) and that positive emotions were associated with risk-taking as long as potential losses were perceived as low (Isen and Patrick 1983). Finally, the fact that we found the positive group to perceive less risk than the neutral group is in accordance with Nygren et al. (1996), and more generally the mood maintenance hypothesis (Isen and Patrick 1983) because this hypothesis holds people in positive emotional states to be prone to risk aversion when potential losses are large.

In psychology, we add to an ongoing debate regarding the relationship between emotion and risk-taking behavior. Our results corroborate some theories as discussed above and contradict others described in the literature review. Our chief theoretical and practical contribution was that we measured the impact of emotions on risk perception in an occupational-like context, rather than in abstract tasks. Additionally, this was the first study to implement rigorous process for measuring emotional state, relative risk perception for real environments, and relate these scores statistically through a data reduction process and pairwise comparisons between independent groups. The results significantly increase our understanding of how emotions may antecede risktaking behavior, knowledge that is critical to eventually understanding how to prevent undesired risk-taking behavior in highly consequential environments.

In light of our findings, we suggest future research to extend testing to hazard recognition and the cognitive processes of decision-making. In fact, having an accurate risk perception will not 
prevent workers to willingly behave unsafely if they deliberately chose to disregard the risks associate with a hazard present or with an action. Also, it would be crucial to understand how emotions influence the first step of the situational awareness process because workers can't perceive the risks associated with the hazards surrounding them if they are not aware of the existence of these hazards. A framework for future research is illustrated in Figure 8.

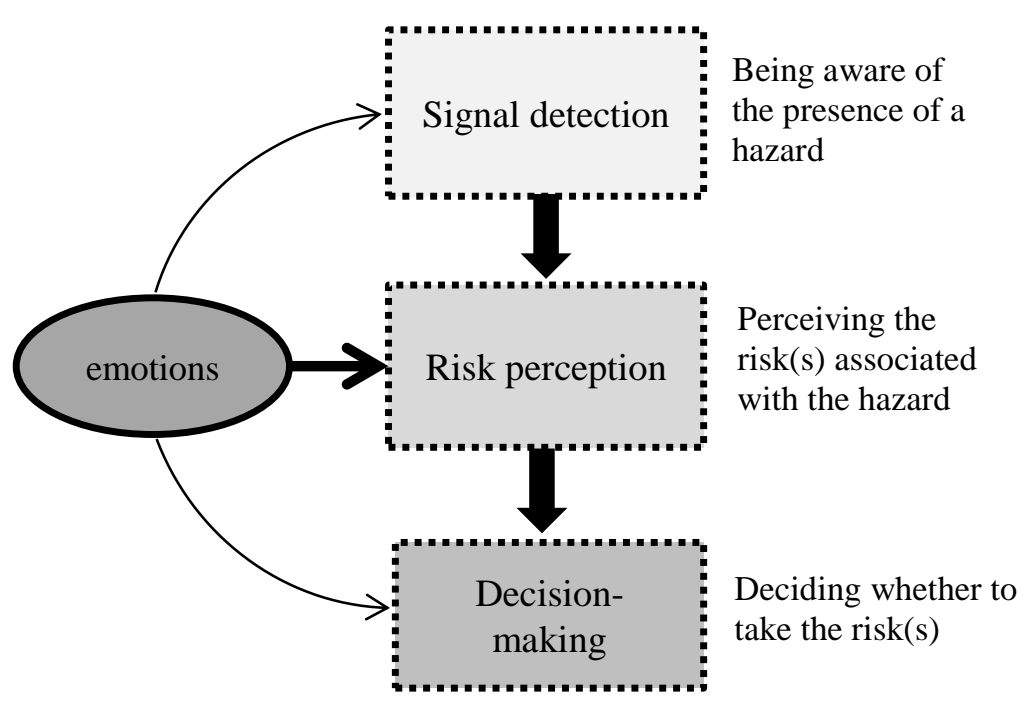

Figure 8 - Framework for future research at the intersection of psychology, human factors engineering, and construction

\section{Potential limitations and justification}

First, our study only involved students. Even though they belonged to Civil, Environmental and Architectural Engineering Department and can be assumed to have at least some understanding of the construction domain, they represent a population very different from construction workers. As discussed, however, the results are both internally and externally valid because students are less subject to experiential biases. Thus, we claim that if not directly to construction workers, the 
results theoretically extend to a broad population because the experiment minimized external biases.

Second, our subjects were all young, and shared the same occidental Anglo-Saxon culture. However, psychologists broadly agree that emotions do not lose all meaning across cultural boundaries (Elfenbein and Ambady 2002), thereby increasing the generalizability of our results across cultures (e.g., Hispanic). Indeed, Matsumoto (1989) claimed that basic emotions are transcultural because they are biologically programmed. Similarly, Russel (1994) argued that broad emotional dimensions, such as valence and intensity, are universal.

Third, we had a relatively small sample size of 61 final participants. We did not have enough participants in the neutral group (10) to test for differences with the other groups. The fact that PCA tended to cluster emotions via affect (positivity/negativity) prevented us from adequately testing the impact of specific emotions alone on risk perception. Rather, we tested the impact of affect (positive and negative emotional states) on risk-perception. Future researchers are encouraged to build on this study with a larger dataset.

Finally, the usefulness of our results depends on whether past researchers are correct in their theories about the nature of the relationship between emotions, risk perception and risk-taking. We, therefore, highly suggest empirical testing of the hypothesis within the construction domain. 


\section{REFERENCES}

Agarwal, P. \& Everett, J. G. (1997). Strategies for construction contractors to reduce workers' compensation costs, Journal of Management in Engineering, 13(5), pp. 70-75.

Aranda, G., and E. Finch. 2003. "Using Repertory Grids to Measure Changes in Risk-taking Behavior." Journal of Construction Research 4 (1): 101-114.

Arrindell, W. A., \& van der Ende. J. (1985). An empirical test of the utility of the observationsto-variables ratio in factor and components analysis. Applied Psychological Measurement, 9, 165 $-178$.

Artman, H. (2000). "Team situation assessment and information distribution." Ergonomics, 43(8): 1111-1128.

Baradan, S. and M. A. Usmen (2006). "Comparative Injury and Fatality Risk Analysis of Building Trades." Journal of Construction Engineering and Management 132(5): 533-539.

Bargh, J. A. (1984). Automatic and conscious processing of social in- formation. In R. S. Wyer, Jr., \& T. K. Srull (Eds.), Handbook of social cognition (Vol. 3, pp. 1-44 ). Hillsdale, N J: Edbaum.

Bargh, J.A. \& Ferguson, M.J. (2000). Beyond behaviorism: The automaticity of higher mental processes. Psychological Bulletin, 126, 925-945.

Bechara A, Damasio H, Tranel D, Damasio AR (1997). "Deciding advantageously before knowing the advantageous strategy". Science 275 (5304): 1293-5.

Bonnet, A., L. Fernandez, A. Piolat, J. L. Pedinielli, and others. 2008. "Changes in Emotional States Before and After Risk Taking in Scuba Diving." Journal of Clinical Sport Psychology 2 (1): 25-40.

Boyle, Gregory J. 1984. "Reliability and Validity of Izard's Differential Emotions Scale." Personality and Individual Differences 5 (6): 747-750.

Bureau of Labor Statistics (2011). Occupational Injuries/Illnesses and Fatal Injuries Profiles. <http://www.bls.gov/news.release/pdf/cfoi.pdf>. Last accessed July 18, 2012.

Bryant, F. B., \& Yarnold, P. R. (1995). Principal-components analysis and confirmatory factor analysis. In L. G.

Carter, G. and Smith S.D. (2006). "Safety hazard identification on construction projects." Journal of Construction Engineering and Management, 132(2): 197-205

Center to Protect Workers' Rights (CPWR) (2002) The Construction Chart Book, 2nd edn (Silver Spring, MD:CPWR Publishing). 
Cisler J. M., Bacon A. K., Williams N.L. Phenomenological characteristics of attentional biases towards threat: a critical review. Cognitive Therapy and Research. 2009;33:221-234

Clore, G. L., Schwarz, N., \& Conway, M. (1994). Affective causes and consequences of social information processing. In R. S. Wyer, \& T. K. Srull (Eds.), Handbook of social cognition (2nd ed.; Vol. 1, pp. 323-417). Hillsdale, NJ: Erlbaum

Construction Industry Institute (CII) Research Team 293 (2013). "Strategies for Safety and Health Hazard Recognition." Research Summary 293-1, Austin, TX, 2013, Authors: Hallowell, M.R., Kleiner, B., Albert, A., Duncan, J.

Cooper, M. Lynne, Phillip K. Wood, Holly K. Orcutt, and Austin Albino. 2003. "Personality and the Predisposition to Engage in Risky or Problem Behaviors During Adolescence." Journal of Personality and Social Psychology 84 (2): 390-410. doi:10.1037/0022-3514.84.2.390

Comrey, A. L., \& Lee, H. B. (1992). A first Course in Factor Analysis. Hillsdale, NJ: Erlbaum.

Costello, A. B., \& Osborne, J. W. (2005). Best practices in exploratory factor analysis: Four recommendations for getting the most from your analysis. Practical Assessment Research \& Evaluation, 10(7). Retrieved July 3, 2008 from http://pareonline.net/pdf/v10n7a.pdf.

Dahlback, Olaf. 1991. "Accident-proneness and Risk-Taking." Personality and Individual Differences 12 (1): 79-85.

DeSteno, David; Petty, Richard E.; Wegener, Duane T.; Rucke, Derek D. Journal of Personality and Social Psychology, Vol 78(4), Apr 2000, 707. doi: 10.1037/h0087886

Drevets, W. C., and M. E. Raichle. 1998. "Reciprocal Suppression of Regional Cerebral Blood Flow During Emotional Versus Higher Cognitive Processes: Implications for Interactions Between Emotion and Cognition.” Cognition and Emotion 12 (3): 353-385.

Droit-Volet, Sylvie, Sophie L. Fayolle, and Sandrine Gil. 2011. "Emotion and Time Perception: Effects of Film-Induced Mood.” Frontiers in Integrative Neuroscience 5. doi:10.3389/fnint.2011.00033. http://www.frontiersin.org/Integrative_Neuroscience/10.3389/fnint.2011.00033/abstract.

Ekman, P. (1992a). Are there basic emotions? Pyschological Review, 99,550-553.

Ekman, P. (1984). Expression and the nature of emotion. In K. Scherer \& P. Ekman (Eds.), Approaches to emotion (pp. 319-344). Hillsdale, NJ: Lawrence Erlbaum.

Ekman, P., Friesen, W. V., \& Ellsworth, P. (1982). What emotion categories or dimensions can observers judge from facial behavior? In P. Ekman (Ed.), Emotion in the human face (p39-55). New-York: Cambridge University Press. 
Elfenbein, Hillary Anger, and Nalini Ambady. 2002. "On the Universality and Cultural Specificity of Emotion Recognition: A Meta-analysis." Psychological Bulletin 128 (2): 203-235. doi:10.1037//0033-2909.128.2.203.

Eisenberg, A. E., Baron, J., \& Seligman, M. E. P. (1996). Individual differences in risk aversion and anxiety. Accessed May 31, 2013.

http://www.sas.upenn.edu/ baron/papers.htm/amyold.html\#5.

Endsley, M.R. (1995). "Measurement of situation awareness in dynamic systems." Human Factors, 37(1): 65-84.

Fessler, Daniel M.T., Elizabeth G. Pillsworth, and Thomas J. Flamson. 2004. "Angry Men and Disgusted Women: An Evolutionary Approach to the Influence of Emotions on Risk Taking." Organizational Behavior and Human Decision Processes 95 (1) (September): 107-123. doi:10.1016/j.obhdp.2004.06.006.

Field, Andy, Miles, Jeremy and Field, Zoë (2012) Discovering Statistics Using R. Sage Publications. ISBN 978-1446200469

Finucane, M.L., Alhakami, A., Slovic, P., \& Johnson, S.M. (2000).

The affect heuristic in judgments of risks and benefits. Journal of Behavioral Decision Making, $13,1-17$.

Fitness, J., \& Fletcher, G. J. O. (1993). Love, hate, anger, and jealousy in close relationships: A prototype and cognitive appraisal analysis. Journal of Personality and Social Psychology, 65, 942-958.

Garson, D. G. (2008). Factor Analysis: Statnotes. Retrieved March 22, 2008, from North Carolina State University Public Administration Program, http://www2.chass.ncsu.edu/garson/pa765/factor.htm.

Gilboa, E., \& Revelle, W. (1994). Personality and the structure of emotional responses. In S. Van Goozen, N. E. Van de Poll, \& J. A. Sargent (Eds.), Emotions: Essays on current issues in the field of emotion theory (pp. 135-159). Hillsdale, NJ: Erlbaum.

Gorsuch, R. L. (1983). Factor analysis ( $2^{\text {nd }}$ ed.). Hillsdale, NJ: Lawrence Erlbaum Associates.

Greene, A., D. Root, and T. Thorpe. 2000. "The Comfort Blanket of Risk Assessment: An Investigation into the Subjective Assessment of Risk." In Proceedings of the 16th Annual ARCOM Conference, 241-249. http://www.arcom.ac.uk/publications/procs/ar2000-241249_Greene_Root_and_Thorpe.pdf.

Gross, J. J., \& Levenson, R. W. (1995). Emotion elicitation using films. Cognition and Emotion, 9, 87-108. 
Griskevicius, V., Goldstein, N. J., Mortensen, C. R., Sundie, J. M., Cialdini, R. B., Kenrick, D. G. 2009."Fear and loving in Las Vegas: evolution, emotions, and persuasion." Journal of Marketing Research 46 (June): 384-395.

Guadagnoli, E., \& velicer, W. F. (1988). Relation of sample size to the stability of component patterns. Psychological bulletin, 103, 265-275.

Hallowell, Matthew. 2010. "Safety Risk Perception in Construction Companies in the Pacific Northwest of the USA." Construction Management and Economics 28 (4) (April): 403-413. doi:10.1080/01446191003587752.

Hallowell, Matthew R., and John A. Gambatese. 2010. "Population and Initial Validation of a Formal Model for Construction Safety Risk Management." Journal of Construction Engineering and Management 136 (9): 981-990.

Hallowell, M. and Gambatese, J.A. (2007). Quantification and Communication of Construction Safety Risk. Evolution of and Directions in Construction Safety and Health, CIB W99 Working Commission Rinker International Conference, Gainesville, FL, March 9-11, 2008.

Harmon-Jones, E., Amodio, D. M., \& Zinner, L. R. (2007). Social psychological methods in emotion elicitation. In J. A. Coan and J. J. B. Allen (Eds.) Handbook of emotion elicitation and assessment (pp. 91-105), New York: Oxford University Press.

Hatcher, Larry. 1994. A Step-by-step Approach to Using the SAS System for Factor Analysis and Structural Equation Modeling. SAS press.

Heinrich, H. W., Peterson, D., and Roos, N. (1980). Industrial Accident Prevention. McGrawHill, New York.

Hinze, J. (2006). Construction Safety. New York: Prentice Hall.

Hinze, J.W. 1997. Construction Safety. Prentice Hall PTR.

Hinze, J. (1996). "The distraction theory of accident causation."

Proceedings of the International Conference On Implementation of Safety and Health on Construction Sites, CIB Working Commission W99: Safety and Health on Construction Sites, L. M. Alvez Diaz and R. J. Coble, eds, Balkema, Rotterdam, The Netherlands, pp. 357-384. Howell, G. A., G. Ballard, T. S. Abdelhamid, and P. Mitropoulos. 2002. "Working Near the Edge: a New Approach to Construction Safety." In ANNUAL CONFERENCE ON LEAN CONSTRUCTION, 10:49-60. http://www.leanconstruction.org/pdf/SafetyWP.pdf.

Isen, A. M., and R. Patrick. 1983. "The Effect of Positive Feelings on Risk Taking: When the Chips Are Down.” Organizational Behavior and Human Performance 31 (2): 194-202.

Izard, C. E. (1992). Basic emotions, relations among emotions, and emotion-cognition relations. Psychological Review, 99, 561-565. 
Izard, C. E. Patterns of emotions: A new analysis of anxiety and depression. New York: Academic, 1972.

Izard, C. E. The face of emotion. New York: Appleton-Century-Crofts, 1971.

International Labor Organization (1983). Accident Prevention, A Workers' Education Manual. Geneva, Switzerland.

Joliffe, I. (1986). Principal Components Analysis, Springer, Verlag.

Johnson, E. J., Tversky, A., 1983. Affect, generalization and the perception of risk. Journal of Personality and Social Psychology 45, 20-31.

Kahneman, D., and D. Lovallo. 1993. "Timid Choices and Bold Forecasts: A Cognitive Perspective on Risk Taking." Management Science: 17-31.

Keller, C., Siegrist, M. and Gutscher, H. (2006). "The Role of the Affect and Availability Heuristics in Risk Communication,” Risk Analysis, 26(3) (June), 631-639. doi:10.1111/j.1539-6924.2006.00773.x.

Kelley, A. M., W. D. Killgore, J. R. Athy, and M. Dretsch. 2010. "Risk Propensity, Risk Perception, and Sensation Seeking in US Army Soldiers: A Preliminary Study of a Risk Assessment Task Battery". DTIC Document. http://oai.dtic.mil/oai/oai?verb=getRecord\&metadataPrefix=html\&identifier=ADA511524.

Klumb, P. L. (1995). "Cognitive failures and performance differences: Validation studies of a German version of the cognitive failures questionnaire." Ergonomics, vol.38, no. 7, 1456-1467.

Kline, P. (2002). An easy guide to factor analysis. London: Routledge.

Kim, J.O., \& Mueller, C. W. (1978). Introduction to factor analysis: What it is and how to do it. Beverly Hills, CA: Sage.

Keller, Carmen, Michael Siegrist, and Heinz Gutscher. 2006. "The Role of the Affect and Availability Heuristics in Risk Communication." Risk Analysis 26 (3) (June): 631-639.

Karama, Sherif, Jorge Armony, and Mario Beauregard. 2011. "Film Excerpts Shown to Specifically Elicit Various Affects Lead to Overlapping Activation Foci in a Large Set of Symmetrical Brain Regions in Males." Edited by Jan Lauwereyns. PLoS ONE 6 (7) (July 27): e22343. doi:10.1371/journal.pone.0022343.

Karama, Sherif, Jorge Armony, and Mario Beauregard. 2011. "Film Excerpts Shown to Specifically Elicit Various Affects Lead to Overlapping Activation Foci in a Large Set of Symmetrical Brain Regions in Males.” Edited by Jan Lauwereyns. PLoS ONE 6 (7) (July 27): e22343. doi:10.1371/journal.pone.0022343. 
Lerner, J. S., and D. Keltner. 2000. "Beyond Valence: Toward a Model of Emotion-specific Influences on Judgement and Choice.” Cognition \& Emotion 14 (4): 473-493.

Lynn, Spencer K., Xuan Zhang, and Lisa Feldman Barrett. 2012. “Affective State Influences Perception by Affecting Decision Parameters Underlying Bias and Sensitivity." Emotion 12 (4): 726-736. doi:10.1037/a0026765.

LeDoux JE, ed. 1996.The Emotional Brain.New York: Simon \& Schuster

Loewenstein, G., Weber, E. U., Hsee, C. K. and Welch, N. (2001). Risk as feelings.Psychological Bulletin127: 267-286.

Loewenstein, G., \& Lerner, J. S. (2003). The role of affect in decision making. In R. Davidson, K. Scherer \& H. Goldsmith (Eds.), Handbook of affective science (pp. 619-642). New York: Oxford University Press.

Massey, W.F. (1965) Principal components regression in exploratory statistical research. Journal of American Statistical Association, 60, 234-246.

MacCallum, R. C., Widaman, K. F., Preacher, K. J., \& Hong S. (2001). Sample size in factor analysis: The role of model error. Multivariate Behavioral Research, 36, 611-637.

MacCallum, R. C., Widaman, K. F., Zhang, S., \& Hong S. (1999). Sample size in factor analysis. Psychological Methods, 4, 84-99.

Matsumoto, D. 1989. "Cultural Influences on the Perception of Emotion.” Journal of CrossCultural Psychology 20 (1) (March 1): 92-105. doi:10.1177/0022022189201006.

Matsumoto, David. 1987. "The Role of Facial Response in the Experience of Emotion: More Methodological Problems and a Meta-analysis." Journal of Personality and Social Psychology 52 (4): 769-774.

Muthén, B. (2004). Latent variable analysis: Growth mixture modeling and related techniques for longitudinal data. In D. Kaplan (ed.), Handbook of quantitative methodology for the social sciences (pp.345-368). Newbury Park, CA: Sage Publications.

Muthén, B., \& Kaplan D. (1985). A comparison of some methodologies for the factor analysis of non-normal Likert variables. British Journal of Mathematical and Statistical Psychology, 38, 171-189.

Norman GR, Streiner DL. Biostatistics: The Bare Essentials (3rd edition) Hamilton, B.C. Decker, 2007

Nygren, T. E., A. M. Isen, P. J. Taylor, and J. Dulin. 1996. "The Influence of Positive Affect on the Decision Rule in Risk Situations: Focus on Outcome (and Especially Avoidance of Loss) 
Rather Than Probability." Organizational Behavior and Human Decision Processes 66 (1): 5972.

Öhman, A., \& Mineka, S. (2001). Fear, phobias and preparedness: Toward an evolved module of fear and fear learning. Psychological Review,108, 483-522.

Ortony, A., Clore, G.L., and Collins, A. (1988). The cognitive structure of emotions. New York: Cambridge University Press.

Osborne, J. W., \& Costello, A. B. (2004). Sample size and subject to item ratio in principal components analysis.

Practical Assessment, Research \& Evaluation, 9(11). Retrieved July 1, 2008 from http://PAREonline.net/getvn.asp?v=9\&n=11.

Patrick, C. J. 1994. "Emotion and Psychopathy: Startling New Insights.” Psychophysiology 31 (4): 319-330.

Petersen, D, (1982). "Human Error-reduction and Safety Management."STMP Press, New York, N.Y.

Perrow, C. (1984):Normal Accidents: Living with High-Risk Technologies. New York, Basic Books.

Philippot, P., Schaefer, A., \& Herbette, G. (2003). Consequences of specific processing of emotional information: Impact of general versus specific autobiographical memory priming on emotion elicitation. Emotion, 3, 270-283

Philippot, Pierre, Gaëtane Chapelle, and Sylvie Blairy. 2002. "Respiratory Feedback in the Generation of Emotion.” Cognition \& Emotion 16 (5) (August): 605-627. doi:10.1080/02699930143000392.

Pfister, H.-R., \& Böhm, G. (2008). The multiplicity of emotions: a framework of emotional functions in decision making. Judgment and decision-making, 3(1): 5-17,

Pfister, H.-R., and Böhm, G. (2000). "The multiplicity of emotions: A framework of emotional functions in decision making." Judgment and Decision Making, vol. 3, no. 1, January 2008, pp. 5-17.

Preacher, K. J., \& MacCallum, R. C. (2002). Exploratory Factor Analysis in Behavior Genetics Research: Factor Recovery with Small Sample Sizes. Behavior Genetics, 32, 153-161.

Raghunathan, R., and M. T. Pham. 1999. “All Negative Moods Are Not Equal: Motivational Influences of Anxiety and Sadness on Decision Making." Organizational Behavior and Human Decision Processes 79: 56-77 
Recht, J. (1970). Systems Safety Analysis: Error Rates and Costs. National Safety Council, Chicago.

Reason, J. T. (1990). Human Error. Cambridge University Press, New York.

Reason, J. (1990) The contribution of latent human failures to the breakdown of complex systems. Philosophical Transactions of the Royal Society (London), series B. 327: 475-484.

Ross, L. Lepper, M. R., \& Hubbard, M. (1975). Perseverance in self-perception and social perception: Biased attributional processes in the debriefing paradigm. Journal of Personality and Social Psychology, 32, 880-892.

Rottenberg, J., Ray, R. R., \& Gross, J. J. (2007). Emotion elicitation using films. In J. A. Coan \& J. J.B. Allen (Eds.), The handbook of emotion elicitation and assessment (pp. 9_28). New York: Oxford University Press.

Russell, J. A. (1994). Is there universal recognition of emotion from facial expression? A review of the cross-cultural studies.

Psychological Bulletin, 115,102-141

Russell, J.A. (1991). In defense of a prototype approach to emotion concepts. Journal of Personality and Social Psychology, 60, 37-47.

Sarter, N.B. and Woods, D.D. (1991). "Situation awareness: A critical but ill-defined phenomenon." International Journal of Aviation Psychology, 1, 45-57.

Sawacha, E., Naoum, S. and Fong, D. (1999). Factors affecting safety performance on construction sites. International Journal of Project Management, 17(5): 309-31.

Schaefer, Alexandre, and Pierre Philippot. 2005. "Selective Effects of Emotion on the Phenomenal Characteristics of Autobiographical Memories." Memory 13 (2) (February): 148160. doi:10.1080/09658210344000648.

Schaefer, A., Collette, F., Philippot, P., Van der Linden, M., Laureys, S., Delfiore, G., Degueldre, C., Maquet, P., Luxen, A., and Salmon, E., 2003. "Neural Correlates of 'hot' and 'cold' Emotional Processing: a Multilevel Approach to the Functional Anatomy of Emotion." NeuroImage 18 (4) (April): 938-949. doi:10.1016/S1053-8119(03)00009-0.

Schaefer, A., Fletcher, K., Pottage, C. L., Alexander, K., and Brown, C., 2009. "The Effects of Emotional Intensity on ERP Correlates of Recognition Memory." NeuroReport 20 (3)

(February): 319-324. doi:10.1097/WNR.0b013e3283229b52.

Schaefer, Alexandre, Frédéric Nils, Xavier Sanchez, and Pierre Philippot. 2010. “Assessing the Effectiveness of a Large Database of Emotion-eliciting Films: A New Tool for Emotion Researchers." Cognition \& Emotion 24 (7) (November): 1153-1172. doi:10.1080/02699930903274322. 
Schimmack, Ulrich. 2003. "Affect Measurement in Experience Sampling Research.” Journal of Happiness Studies 4 (1): 79-106.

Schwarz, N., \& Clore, G. L. (2007). Feelings and phenomenal experiences. In A. Kruglanski \& E. T. Higgins (eds.), Social psychology. Handbook of basic principles ( $2^{\text {nd }}$ ed.; pp. 385-407). New York: Guilford.

Schwarz, N., and G. L. Clore. 1996. "Feelings and Phenomenal Experiences." Social Psychology: Handbook of Basic Principles 2: 385-400.

Schwarz, N., \& Clore, G. L. (1983). Mood, misattribution, and judgments of well-being: Informative and directive functions of affective states. Journal of Personality and Social Psychology, 45, 513-523.

Simon, L., Greenberg, J., Harmon-Jones, E., Solomon, S., Pyszczynski, T., \& Abend, T. (1997). Terror management and cognitive experiential self-theory: Evidence that terror management occurs in the experiential system. Journal of Personality and Social Psychology, 72, 1132-1146

Slater, M. 2009. "Place Illusion and Plausibility Can Lead to Realistic Behaviour in Immersive Virtual Environments." Philosophical Transactions of the Royal Society B: Biological Sciences 364 (1535) (November 2): 3549-3557. doi:10.1098/rstb.2009.0138.

Slovic, P., Finucane, M. L., Peters, E., \& MacGregor, D. G. (2004). "Risk as Analysis and Risk as Feelings: Some Thoughts about Affect, Reason, Risk, and Rationality", Risk Analysis, 24(2), 311-322.

Slovic, P., Fishhoff, B., \& Lichtenstein, S. (1980). Facts and Fears: Understanding Perceived Risk. In Albers, W.A. (Ed.), Societal Risk Assessment: How Safe Is Safe Enough? New York, NY: Plenum Press.

Smith, K., and Hancock, P.A. (1995). "Situation awareness is adaptive, externally directed consciousness." Human Factors, 37(1): 137-148.

Sonnemans, Joep and Nico Frijda (1995) The Determinants Of Subjective Emotional Intensity. Cognition Emotion 9, 483-506

Swain, A.D., Altman, J.W., \& Rook, L.W., Jr. (1963). Human error quantification. A symposium. SCR-610.

Albuquerque: Sandia Corporation.

Tabachnick, B. G., \& Fidell, L. S. (2007). Using multivariate statistics (5th ed.). Upper Saddle River, NJ: Pearson Allyn \&Bacon.

Tabachnick, B.G., \& Fidell, L.S. (2001). Using Multivariate Statistics ( $4^{\text {th }}$ edition.). Boston, MA, Allyn and Bacon. 
Taylor, Shelley and Jonathan Brown (1988). Psychological Bulletin, 103(2), American Psychological Association, pp. 193-210.

Velicer, W. F., \& Fava, J. L. (1998). Effects of variable and subject sampling on factor pattern recovery. Psychological Methods, 3, 231-251.

Velten, Emmett. 1968. "A Laboratory Task for Induction of Mood States." Behaviour Research and Therapy 6 (4): 473-482.

Veltri, A., and J. Ramsay. 2009. "Economic Analysis Make the Business Case For SH\&E." Professional Safety 54 (9). http://www.onepetro.org/mslib/servlet/onepetropreview?id=ASSE09-09-22.

Verduyn, P., F. Tuerlinckx, and K. Van Gorp. 2011. "Measuring the Duration of Emotional Experience: The Influence of Actual Duration and Response Format." Quality \& Quantity: 1-11.

Verduyn, P., Van Mechelen, I., Tuerlinckx, F., Meers, K., \& Van Coillie, H. (2009b). Intensity profiles of emotional experience over time.

Cognition \& Emotion, 23,1427-1443.

von Leupoldt, A., Rohde, J., Beregova, A., Thordsen-Sorensen, I., Zur Nieden, J., \& Dahme, B. (2007). Films for eliciting emotional states in children. Behavior Research Methods, 39, 606 609.

Waehrer, Geetha M., Xiuwen S. Dong, Ted Miller, Elizabeth Haile, and Yurong Men. 2007. "Costs of Occupational Injuries in Construction in the United States." Accident Analysis \& Prevention 39 (6) (November): 1258-1266. doi:10.1016/j.aap.2007.03.012.

Perrow, Charles. 1984. "Normal Accidents: Living with High-Risk Technologies". Basic Books, New-York.

Wilde, G. J. S. 1998. "Risk Homeostasis Theory: An Overview.” Injury Prevention 4 (2): 89.

Wilson, Timothy D., Aronson, Elliot, and Carlsmith, Kevin. 2010. "The Art of Laboratory Experimentation". in Fiske, Susan T., Daniel T. Gilbert, and Gardner Lindzey. The handbook of social psychology, $5^{\text {th }}$ edition. New York: John Wiley \& Sons. p70.

Yuen, Kenneth S.L, and Tatia M.C Lee. 2003. "Could Mood State Affect Risk-taking Decisions?” Journal of Affective Disorders 75 (1) (June): 11-18. doi:10.1016/S01650327(02)00022-8.

Zemack-Rugar, Yael, James R. Bettman, and Gavan J. Fitzsimons. 2007. "The Effects of Nonconsciously Priming Emotion Concepts on Behavior." Journal of Personality and Social Psychology 93 (6): 927-939. doi:10.1037/0022-3514.93.6.927. 
Zwick, William R., and Wayne F. Velicer. 1986. "Comparison of Five Rules for Determining the Number of Components to Retain.” Psychological Bulletin 99 (3): 432-442. doi:10.1037/00332909.99.3.432. 


\section{POST FILM QUESTIONNAIRE}

I watched the clip (number on the sticky note): \#

The following questions refer to how you felt while watching the film excerpt:

\begin{tabular}{|c|c|c|c|c|c|c|c|}
\hline 0 & 1 & 2 & 3 & 4 & 5 & 6 & 8 \\
\hline $\begin{array}{l}\text { Not at all/ } \\
\text { none }\end{array}$ & & & & $\begin{array}{l}\text { Somewhat/ } \\
\text { some }\end{array}$ & & & $\begin{array}{l}\text { Extremelyl } \\
\text { a great deal }\end{array}$ \\
\hline
\end{tabular}

Using the scale above, please indicate (from 0 to 8) the greatest amount of EACH emotion you experienced while watching the movie excerpt:

amusement
anger
anxiety
confusion
contempt
disgust

embarrassment
fear
guilt
happiness
interest
joy

\begin{tabular}{l} 
love \\
pride \\
sadness \\
shame \\
\hline surprise \\
\hline unhappiness
\end{tabular}

Did you feel any other emotion during the film? No Yes

If so, what was the emotion?

How much of this emotion did you feel?

Please use the following pleasantness scale to rate the feelings you had during the viewing. Circle your answer:

$\begin{array}{lrllllllc}0 & 1 & 2 & 3 & 4 & 5 & 6 & 7 & \begin{array}{c}8 \\ \text { (unpleasant) }\end{array}\end{array}$

Had you seen this movie before? No Yes 